\title{
Cestode larvae excite host neuronal circuits via glutamatergic signaling.
}

Hayley Tomes ${ }^{* 1,2}$, Anja de Lange ${ }^{* 1,2}$, Ulrich Fabien Prodjinotho ${ }^{3}$, Siddhartha Mahanty ${ }^{4}$, Katherine Smith ${ }^{2,5}$, William Horsnell ${ }^{2,6,7}$, Chummy Sikasunge ${ }^{8}$, Clarissa Prazeres da Costa ${ }^{3}$, Joseph Valentino Raimondo ${ }^{1,2}$

\section{*Authors contributed equally}

${ }^{1}$ Division of Cell Biology, Department of Human Biology, Neuroscience Institute and Institute of Infectious Disease and Molecular Medicine, Faculty of Health Sciences, University of Cape Town, Cape Town, South Africa

${ }^{2}$ Institute of Infectious Disease and Molecular Medicine, Faculty of Health Sciences, University of Cape Town, Cape Town, South Africa

${ }^{3}$ Institute for Medical Microbiology, Immunology and Hygiene, Center for Global Health, Technical University Munich (TUM), Munich, Germany

${ }^{4}$ Department of Medicine, The Peter Doherty Institute for Infection and Immunity and the Victorian Infectious Diseases Service, University of Melbourne, Melbourne, Australia

5 Institute of Infection and Immunity, Cardiff University, Cardiff, UK

${ }^{6}$ Institute of Microbiology and Infection, University of Birmingham, Birmingham, United Kingdom

${ }^{6}$ Laboratory of Experimental and Molecular Immunology and Neurogenetics (INEM), UMR 7355 CNRSUniversity of Orleans, Orleans, France

${ }^{8}$ School of Veterinary Medicine, Department of Paraclinicals, University of Zambia, Lusaka, Zambia

\section{Correspondence:}

Joseph V. Raimondo

email: joseph.raimondo@uct.ac.za

\section{Keywords}

Cestode, Taenia crassiceps, Taenia solium, neurocysticercosis, glutamate, seizures, epilepsy

\section{Acknowledgements}

Dr Philip Fortgens: Division of Chemical Pathology, Department of Pathology, University of Cape Town and National Health Laboratory Service (affiliation when the analyses were done). Current affiliation: Dietrich, Voigt, Mia \& Partners (PathCare) and honorary senior lecturer. Research leading to these results. The research leading to these results has received funding from a Royal Society Newton Advanced Fellowship (NA140170) and a University of Cape Town Start-up Emerging Researcher Award to JVR and grant support from the Blue Brain Project, the National Research Foundation of South Africa, Wellcome Trust and the FLAIR Fellowship Programme (FLR\R1\190829): a partnership between the African Academy of Sciences and the Royal Society funded by the UK Government's Global Challenges Research Fund. CS, UFP and CPdC were supported by the Federal Ministry of Education and Research of Germany (BMBF), Project title: "CYSTINET-Africa” (01KA1610, Germany II). The funders had no role in study design, data collection and analysis, decision to publish, or preparation of the manuscript. 


\section{Abstract}

51 Neurocysticercosis (NCC) is caused by the presence of Taenia solium larvae in the brain and is the

52 leading cause of adult-acquired epilepsy worldwide. However, little is known about how seizures

53 emerge in NCC. To address this knowledge gap we used whole-cell patch-clamp electrophysiology and

54 calcium imaging in rodent hippocampal organotypic slice cultures to identify direct effects of cestode

55 larval products on neuronal activity. We found both whole cyst homogenate and excretory/secretory

56 (E/S) products of Taenia larvae have an acute excitatory effect on neurons, which trigger seizure-like

57 events in vitro. Underlying this effect was Taenia-induced neuronal depolarization, which was mediated by glutamate receptor activation but not by nicotinic acetylcholine receptors, acid-sensing ion channels nor Substance P. Glutamate assays revealed the homogenate of both Taenia crassiceps and Taenia solium larvae contained high concentrations of glutamate and that larvae of both species consistently produce and release this excitatory neurotransmitter into their immediate environment. 


\section{Author summary}

65 Brain infection by larvae of the tapeworm Taenia solium (neurocysticercosis or NCC) is the leading

66 cause of acquired epilepsy in adulthood. Little is understood about the mechanisms by which larvae

67 cause seizures. To address this, we used electrophysiological and imaging techniques in rodent brain

68 slices to investigate how tapeworm larvae directly impact neuronal function. We discovered that both

69 the homogenate and secretory products of tapeworm larvae excite neurons and can trigger seizure-

70 like events in brain slices. This effect was caused by the activation of glutamate receptors and not by

71 activating other types of receptors in the brain. Finally, we observed that tapeworm larvae both

72 contain and release the neurotransmitter glutamate into their immediate environment. These findings

73 are relevant for understanding how tapeworm larvae cause seizures in NCC. 
Introduction

Neurocysticercosis (NCC) is the most prevalent parasitic infection of the central nervous system (CNS) $(1,2)$. It is caused by the presence of Taenia solium ( $T$. solium) larvae in the brain (3). The most common symptom of NCC is recurrent seizures (4). As a result, NCC is the leading cause of adult-acquired epilepsy worldwide (5), resulting in significant morbidity and mortality. In endemic areas, approximately $29 \%$ of people with epilepsy also have NCC (6). Despite the impact of NCC, there are a paucity of studies investigating the seizure mechanisms involved (7). As a result, precisely how larvae are involved in seizure generation is still relatively poorly understood.

In NCC seizures may occur at any stage following initial infection (4). It is thought that inflammatory processes in the brain can play an important role in the development of recurrent seizures (8). Previous work exploring seizure development in NCC has therefore typically focused on how the host neuroinflammatory response to larvae might precipitate seizures $(7,9)$. Robinson et al. found, for example, that production of the inflammatory molecule and neurotransmitter, Substance $\mathrm{P}$, produced by peritoneal larval granulomas, can precipitate acute seizures (10). In addition to host-derived substances, cestodes themselves are known to excrete or secrete various products that interact with host cells in their vicinity. Cestode larvae derived factors are known to modulate the activation status of immunocytes such as microglia and dendritic cells $(11,12)$. However, comparatively little is known about how factors contained in, or secreted by, cestode larvae might affect neurons and neuronal networks directly, including whether these may have pro-seizure effects.

To address this, we used whole-cell patch-clamp recordings and calcium imaging in rodent hippocampal organotypic slice cultures to demonstrate the direct effects of larval products on neuronal activity. We find that both the whole cyst homogenate and the excretory/secretory (E/S) products of Taenia crassiceps (T. crassiceps) larvae have a strong, acute excitatory effect on neurons. 
larval induced neuronal depolarization, which was mediated by glutamate receptor activation and not

102 nicotinic acetylcholine receptors, acid-sensing ion channels nor Substance P. Direct measurement of

103 glutamate concentration revealed that the homogenate of both $T$. crassiceps and $T$. solium larvae

104 contain high levels of glutamate. Lastly, we provide evidence that larvae of both species consistently produce and release this excitatory neurotransmitter into their immediate environment; suggesting that parasite released glutamate directly contributes to NCC seizures.

107 
Materials and Methods

Ethics statement

All animal handling, care and procedures were carried out in accordance with South African national

Larvae of $T$. crassiceps (ORF strain) were donated to us by Dr Siddhartha Mahanty (University of week old female C57BL/6 mice. Every 3 months parasites were harvested by peritoneal lavage and washed 6 times in phosphate buffered saline (PBS, 1X, pH 7.4; Sigma-Aldrich) before further processing.

For the preparation of $T$. crassiceps whole cyst homogenate, larvae were stored immediately after containing a protease cocktail inhibitor (1\% vol/vol, Sigma-Aldrich) at a larval:PBS ratio of 1:3. The mixture was centrifuged at $4000 \mathrm{rpm}$ for 20 minutes at $4{ }^{\circ} \mathrm{C}$. The liquid supernatant (between the white floating layer and solid pellet) was collected and sterile filtered through a $0.22 \mu \mathrm{m}$ size filter (MillexGV syringe filter, Merck). This supernatant was then aliquoted and stored at $-80^{\circ} \mathrm{C}$ until use. To assess whether large or small molecules were responsible for the excitation of neurons, a portion of the whole cyst homogenate was dialysed using a Slide-A-Lyzer ${ }^{\mathrm{TM}}$ dialysis cassette $(3 \mathrm{kDa}$ MWCO, Separations) in $2 \mathrm{l}$ of artificial cerebro-spinal fluid (aCSF) at $4^{\circ} \mathrm{C}$. The aCSF solution was changed twice 
6000 analyser (Roche) was used, with ion specific electrodes for $\mathrm{K}^{+}$and $\mathrm{Na}^{+}$. A Mettler Toledo

SevenCompact ${ }^{\mathrm{TM}} \mathrm{pH}$ meter S210 (Merck) was used to determine the $\mathrm{pH}$ of the homogenate.

For the preparation of $T$. crassiceps $\mathrm{E} / \mathrm{S}$ products, after harvesting, washed larvae were maintained for

48-72 hours, stored at $-20^{\circ} \mathrm{C}$ and at the end of the culture period, thawed and pooled. The pooled conditioned medium was termed total excretory/secretory products (total E/S). A portion of the total $\mathrm{E} / \mathrm{S}$ was aliquoted and stored at $-80{ }^{\circ} \mathrm{C}$, while another portion was concentrated (about 100X) and buffer exchanged to PBS using an Amicon stirred cell with a 3 kDa MWCO cellulose membrane (SigmaAldrich). The concentrated product contained T. crassiceps E/S products larger in size than $3 \mathrm{kDa}(\mathrm{E} / \mathrm{S}$ $>3 \mathrm{kDa})$, in PBS (1X). This was aliquoted and stored at $-80^{\circ} \mathrm{C}$. The fraction of the total $\mathrm{E} / \mathrm{S}$ that passed through the $3 \mathrm{kDa}$ membrane $(\mathrm{E} / \mathrm{S}<3 \mathrm{KDa}$, still in medium) was also retained, aliquoted and stored at $-80^{\circ} \mathrm{C}$.

For the preparation of $T$. solium whole cyst homogenate, larvae of $T$. solium were harvested from the muscles of heavily infected, freshly slaughtered pig. After extensive washing with sterile $1 \mathrm{X}$ phosphate buffered saline (PBS; pH 7.4; Sigma-Aldrich), T. solium larvae were suspended in PBS containing phenylmethyl-sulphonyl fluoride $(5 \mathrm{mM})$ and leupeptin $(2.5 \mu \mathrm{M})$ at a larval:PBS ratio of 1:3. Larvae were then homogenised using a sterile hand held homogenizer at $4^{\circ} \mathrm{C}$. The resulting homogenate was sonicated ( $4 \times 60 \mathrm{~s}$ at $20 \mathrm{kHz}, 1 \mathrm{~mA}$, with $30 \mathrm{~s}$ intervals) and gently stirred with a magnetic stirrer for $2 \mathrm{~h}$ at $4^{\circ} \mathrm{C}$. Thereafter it was centrifuged at $15,000 \mathrm{~g}$ for $60 \mathrm{~min}$ at $4{ }^{\circ} \mathrm{C}$ and the liquid supernatant (between the white floating layer and solid pellet) was collected. The supernatant was filtered through 
and T. solium larval products were assessed for protein concentration using a BCA protein or Bradford's assay kit respectively.

For the assessment of daily glutamate production both $T$. crassiceps and $T$. solium larvae were placed penicillin, $100 \mu \mathrm{g} / \mathrm{ml}$ streptomycin, $11.4 \mathrm{U} / \mathrm{ml}$ nystatin and $2 \mathrm{mM}$ glutamax). Every 24 hours $1 \mathrm{ml}$ of culture media were collected from each well, stored at $-80{ }^{\circ} \mathrm{C}$, and replaced with fresh culture medium. The concentration of glutamate was measured using a Glutamate assay kit according to the supplier's instructions (Sigma-Aldrich).

Organotypic brain slices were prepared using 6-8 day old Wistar rats and C57BL/6 mice following the protocol originally described by Stoppini et al., (1991). Brains were extracted and swiftly placed in cold $\left(4^{\circ} \mathrm{C}\right)$ dissection media consisting of Geys Balanced Salt Solution (Sigma-Aldrich) supplemented with D-glucose (Sigma-Aldrich). The hemispheres were separated and individual hippocampi were removed and immediately cut into $350 \mu \mathrm{m}$ slices using a Mcllwain tissue chopper (Mickle). Cold dissection media was used to rinse the slices before placing them onto Millicell-CM membranes (Sigma-Aldrich). Slices were maintained in culture medium consisting of $25 \%$ (vol/vol) Earles balanced salt solution (Sigma-Aldrich); 49 \% (vol/vol) minimum essential medium (Sigma-Aldrich); $25 \%$ (vol/vol) heat-inactivated horse serum (Sigma-Aldrich); 1 \% (vol/vol) B27 (Invitrogen, Life Technologies) and 
Brain slices were transferred to a submerged recording chamber on a patch clamp rig, which was maintained at a temperature between 28 and $30^{\circ} \mathrm{C}$, and were continuously superfused with standard aCSF bubbled with carbogen gas (95\% $\left.\mathrm{O}_{2}: 5 \% \mathrm{CO}_{2}\right)$ using peristaltic pumps (Watson-Marlow). The standard aCSF was composed of: $\mathrm{NaCl}(120 \mathrm{mM}) ; \mathrm{KCl}(3 \mathrm{mM}) ; \mathrm{MgCl}_{2}(2 \mathrm{mM}) ; \mathrm{CaCl}_{2}(2 \mathrm{mM}) ; \mathrm{NaH}_{2} \mathrm{PO}_{4}$ (1.2 $\mathrm{mM}) ; \mathrm{NaHCO}_{3}(23 \mathrm{mM})$ and D-Glucose $(11 \mathrm{mM})$ in deionised water with $\mathrm{pH}$ adjusted to between 7.35 - 7.40 using $0.1 \mathrm{mM} \mathrm{NaOH}$ (Sigma-Aldrich). Neurons in the CA3 region of the hippocampus were visualized using a Zeiss Axioskop or Olympus BX51WI upright microscope using 20x or 40x water-immersion objectives and targeted for recording. Micropipettes were prepared (tip resistance between 3 and $7 \mathrm{M} \Omega$ ) from borosilicate glass capillaries (outer diameter $1.2 \mathrm{~mm}$, inner diameter 0.69 mm, Harvard Apparatus Ltd) using a horizontal puller (Sutter). Recordings were made in current clamp mode using Axopatch 200B amplifiers (Axon Instruments) and data acquired using WinWCP (University of Strathclyde) or Igor (Markram Laboratory, Ecole polytechnique fédérale de Lausanne). Matlab (MathWorks) was utilised for trace analysis. Two internal solutions were used: a "standard" internal solution (K-gluconate (126 mM), KCl (4 mM), HEPES (10 mM) Na ${ }_{2} \mathrm{ATP}(4 \mathrm{mM}), \mathrm{NaGTP}(0.3 \mathrm{mM})$ and $\mathrm{Na}_{2}$-phosphocreatine (10 mM); Sigma-Aldrich) and a "caesium" internal solution ( $\mathrm{CsOH}(120 \mathrm{mM})$, Gluconic acid (120 mM), HEPES (40 mM), Na 2 ATP (2 mM), NaGTP (0.3 mM) and $\mathrm{NaCl}(10 \mathrm{mM})$; Sigma-Aldrich). Experimental substances were puffed onto neurons using an OpenSpritzer, a custom made pressure ejection system (14). Current was injected if required to ensure a neuronal resting membrane potential within $2 \mathrm{mV}$ of $-60 \mathrm{mV}$. In all puffing experiments each data point represents the mean peak puff-induced change in membrane potential from 10 sweeps. In some experiments tetrodotoxin (TTX) $(2 \mu \mathrm{M})$ was added to the aCSF to block voltage-gated sodium channels. For calcium imaging, organotypic hippocampal mouse brain slices were virally transfected with a genetically-encoded $\mathrm{Ca}^{2+}$ reporter (GCAMP6s under the synapsin promoter, AAV1.Syn.GCaMP6s.WPRE.SV40) one day post culture using the OpenSpritzer and imaged 5 days later 
Mightex) and $470 \mathrm{~nm}$ LED (Thorlabs). Images were collected using $\mu$ Manager (15) and analysed using

Caltracer3 beta scripts in Matlab.

Pharmacological manipulations were performed by bath application of drugs using a perfusion system

211 (Watson-Marlow). Mecamylamine, Amiloride, D-AP5 and CNQX were purchased from Tocris.

Kynurenic acid and Substance P were acquired from Sigma-Aldrich.

\section{Data analysis and statistics}

Data was graphed and analysed using Matlab, Microsoft Excel and GraphPad Prism. All data was subjected to a Shapiro-Wilk test to determine whether it was normally distributed. Normally distributed populations were subjected to parametric statistical analyses, whilst skewed data was assessed using non-parametric statistical analyses. Parametric tests included: unpaired student's ttest; paired student's t-test; one-way analysis of variance (ANOVA) with Tukey's post hoc test and repeated measures ANOVA with Tukey's post-hoc test. Non-parametric tests included: Mann-Whitney test; Wilcoxin ranked pairs test; Kruskal Wallis one-way ANOVA with post hoc Dunn's Multiple Comparison test; and Friedman test with post-hoc Dunn's Multiple Comparison test. The confidence interval for all tests was set at $95 \%$. 
Taenia crassiceps homogenate excites neurons and can elicit epileptiform activity.

227 To investigate the potential acute effects of $T$. crassiceps larvae on neurons, $T$. crassiceps larval somatic homogenate was prepared using larvae harvested from the peritonea of mice which were freeze-thawed and homogenized (see Materials and Methods and Fig. 1A). Whole-cell patch-clamp recordings were made from CA3 pyramidal neurons in rodent hippocampal organotypic brain slice cultures and pico-litre volumes of $T$. crassiceps homogenate were directly applied to the soma of neurons using a custom built pressure ejection system (Fig. 1A) (16). Application of the homogenate (20 ms puff) elicited immediate, transient depolarization of the membrane voltage in recordings from both rat and mouse (Fig. 1B) neurons. Increasing the amount of homogenate delivered by increasing the pressure applied to the ejection system resulted in increasingly large membrane depolarization, which could trigger single or multiple action potentials (Fig. 1B, C). Similar puffs of artificial cerebrospinal fluid (aCSF) did not affect the neuronal membrane potential, thereby excluding the possibility that mechanical effects might account for the homogenate-induced depolarization observed.

To further explore the acute excitatory effect of $T$. crassiceps on neurons, neuronal networks and the propagation of network activity, we performed fluorescence $\mathrm{Ca}^{2+}$ imaging in mouse hippocampal organotypic brain slice cultures. Neurons were virally transfected with the genetically-encoded $\mathrm{Ca}^{2+}$ reporter, GCAMP6s, under the synapsin promoter and imaged using widefield epifluorescence microscopy (Fig. 1D and Materials and Methods). To simulate a pro-ictal environment, a low $\mathrm{Mg}^{2+}$ aCSF was used $\left(0.5 \mathrm{mM} \mathrm{Mg}^{2+}\right)$ and neurons in the dentate gyrus were imaged whilst small, spatially restricted puffs of T.crassiceps homogenate were delivered every $15 \mathrm{~s}$ using a glass pipette (Fig. 1D). The cells within the direct vicinity of the puffing pipette showed a sharp increase in fluorescence immediately following the delivery of $T$. crassiceps homogenate (Fig. 1.1E $\mathbf{t}_{1}$ ) for all 3 puffs, indicating $\mathrm{Ca}^{2+}$ entry following membrane depolarization and action potential generation. Interestingly, cells in 
all) puffs (Fig. 1E $\mathbf{t}_{2}$ ). The excitation of these cells could only be as a result of being synaptically connected to the cells that were exposed to the puff itself, as they were not positioned close enough to the puffer pipette to be directly excited by the homogenate. Indeed, a current-clamp recording from a neuron in the same slice (Fig. 1E, inset) indicates that a single, spatially restricted puff of

T. crassiceps homogenate can elicit the onset of a regenerative seizure-like event lasting far longer than the puff itself. Together, these results indicate that $T$. crassiceps larvae homogenate results not just in a transient depolarization of cells in the immediate vicinity of application, but can trigger a wave of excitation that propagates through the brain slice in both space and time. This demonstrates that T. crassiceps homogenate can initiate seizure-like activity under suitable conditions.

Potassium contributes modestly to Taenia crassiceps induced neuronal depolarization.

The extracellular concentration of $\mathrm{K}^{+}\left(\left[\mathrm{K}^{+}\right]_{\mathrm{e}}\right.$, typically $\left.3-4 \mathrm{mM}\right)$ in the brain is considerably lower than the intracellular concentration of $\mathrm{K}^{+}\left(\left[\mathrm{K}^{+}\right]_{\mathrm{i}}\right.$, typically $\left.100 \mathrm{mM}\right)$ of neurons (17), which means that even small changes in $\left[\mathrm{K}^{+}\right]_{\mathrm{e}}$ result in relatively large changes to the transmembrane $\mathrm{K}^{+}$gradient and consequently the reversal potential for $\mathrm{K}^{+}\left(\mathrm{E}_{\mathrm{K}+}\right)$. Due to the fact that constitutively activated $\mathrm{K}^{+}$ conductances, or $\mathrm{K}^{+}$"leak" channels, are the major contributor to the resting membrane potential, addition of extracellular $\mathrm{K}^{+}$and accompanying changes to $\mathrm{E}_{\mathrm{K}_{+}}$result in membrane depolarization (18).

As most cell types tend to have a high $\left[\mathrm{K}^{+}\right]_{\mathrm{i}}$, it is conceivable that the $T$. crassiceps homogenate could have a high $\mathrm{K}^{+}$concentration, which could potentially account for its depolarizing and excitatory effects on neurons. To address this, we first directly measured the ionic composition of the homogenate was $11.4 \mathrm{mM}$ as compared to $3.0 \mathrm{mM}$ in our standard aCSF. The $T$. crassiceps homogenate $\mathrm{Na}^{+}$concentration was $123.9 \mathrm{mM}$, and $144.2 \mathrm{mM}$ for the aCSF. Although the $\mathrm{K}^{+}$ concentration is higher in the homogenate than the aCSF, the ionic composition more closely reflects 
determine what effect application of $11.4 \mathrm{mM} \mathrm{K}^{+}$would have on neurons in our system. Whole-cell patch-clamp recordings in current clamp mode using a standard internal solution and aCSF (see Materials and Methods) were made from CA3 pyramidal neurons in rat hippocampal organotypic brain slice cultures. If necessary, current was injected to ensure that the baseline membrane potential was within $2 \mathrm{mV}$ of $-60 \mathrm{mV}$. To remove membrane potential fluctuations due to synaptic noise, and to prevent regenerative $\mathrm{Na}^{+}$conductances due to voltage-gated sodium channels, $2 \mu \mathrm{M}$ TTX was added to the aCSF. Puffs of aCSF containing $11.4 \mathrm{mM} \mathrm{K}^{+}$were directed toward the soma of recorded neurons. Whilst this did cause a depolarization of the membrane potential, the effect was modest, a median positive shift of only $0.72 \mathrm{mV}($ IQR $0.51-1.04 \mathrm{mV}, \mathrm{N}=8)$ in the membrane potential, which was significantly less than the depolarization caused by puffs of $T$. crassiceps homogenate (median 10.12 mV, IQR $9.93-12.49 \mathrm{mV}, \mathrm{N}=5, \mathrm{p}=0.0016$, Mann-Whitney $\mathrm{U}$ test, Fig. 2A, B, D). Next, to isolate neuronal depolarization induced by $T$. crassiceps homogenate, but not mediated by $\mathrm{K}^{+}$, we performed whole cell patch clamp recordings using a caesium based internal solution (see Materials and Methods), which blocks $\mathrm{K}^{+}$channels. The addition of caesium did not greatly change the positive shift in membrane potential caused by T. crassiceps homogenate (median 13.76, IQR $10.87-17.24 \mathrm{mV}$, $\mathrm{N}=49, \mathrm{p} \leq 0.0489$, Mann-Whitney $\mathrm{U}$ test, Fig. 2C, D). Together, this indicates that although $\mathrm{K}^{+}$in the T. crassiceps homogenate does contribute to membrane depolarization, the majority of the effect is mediated by a different component.

Taenia crassiceps homogenate induced neuronal depolarization is mediated by a small molecule.

Next, to determine the fraction of the $T$. crassiceps homogenate, which underlies the acute excitatory effect on neurons we observed, we used a dialysis membrane to separate the fraction of the homogenate bigger than $3 \mathrm{kDa}$ from the total homogenate. To do so we used a $3 \mathrm{kDa}$ dialysis cassette incubated overnight in standard aCSF. This effectively removed molecules smaller than $3 \mathrm{kDa}$ from the homogenate. When this dialysed $T$. crassiceps was puffed onto the cells in the same recording conditions as in Fig. 2B and C, the depolarizing response was greatly reduced ( $p \leq 0.0003$, 
Mann-Whitney $\mathrm{U}$ test, Fig. $3 \mathrm{~A}-\mathrm{C})$. The median positive shift in membrane potential for dialysed excitatory component of the T. crassiceps homogenate is a molecule smaller than $3 \mathrm{kDa}$.

307

$\underline{\text { Taenia crassiceps excretory/secretory products also cause neuronal depolarization. }}$

Helminths are well known to excrete or secrete products into their immediate environment.

Therefore, having confirmed that a small molecule within the $T$. crassiceps homogenate causes acute larvae could also result in neuronal depolarisation. $T$. crassiceps larvae were cultured in media. The media was collected over a period of 21 days and either used as is (T. crassiceps total E/S products) or separated into two fractions and buffer exchanged to PBS using an Amicon stirred cell with a $3 \mathrm{kDa}$ cellulose membrane. The first fraction contained $\mathrm{E} / \mathrm{S}$ products larger than $3 \mathrm{kDa}$ ( $T$. crassiceps $\mathrm{E} / \mathrm{S}>3 \mathrm{kDa}$ ) in PBS, and the second fraction contained $\mathrm{E} / \mathrm{S}$ products smaller than $3 \mathrm{kDa}$ ( $T$. crassiceps $\mathrm{E} / \mathrm{S}<3 \mathrm{kDa}$ ) in media. To control for possible effects of molecules in the buffers, both media and PBS were independently puffed onto neurons.

Again, CA3 neurons in rat hippocampal organotypic slice cultures were whole-cell patched using a caesium based internal in the presence of $2 \mu \mathrm{M}$ TTX. Brief application of total $T$. crassiceps E/S products using a soma directed puff was sufficient to cause a neuronal depolarization (mean $12.29 \mathrm{mV}, \mathrm{SEM} 1.74 \mathrm{mV}, \mathrm{N}=7$ ) significantly larger than that of the media control (mean $-0.48 \mathrm{mV}$, SEM $0.40 \mathrm{mV}, \mathrm{N}=7, \mathrm{p} \leq$ 0.001, One-way ANOVA, Tukey's post hoc test, Fig. 4A, D, F). Similarly, $T$. crassiceps $\mathrm{E} / \mathrm{S}$ products containing components smaller than $3 \mathrm{kDa}$ evoked a significantly larger shift in membrane potential than the media control (mean $16.09 \mathrm{mV}$, SEM $1.56 \mathrm{mV}, \mathrm{N}=7, \mathrm{p} \leq 0.001$, One- 
products containing components smaller than $3 \mathrm{kDa}$ did not differ significantly than that evoked by the total $E / S$ ( $p>0.05$, One-way ANOVA, Tukey's post hoc test, Fig. 4A, B, F).

However, the T. crassiceps E/S product fraction larger than $3 \mathrm{kDa}$ (mean $1.43 \mathrm{mV}$, SEM $0.43 \mathrm{mV}, \mathrm{N}=8$ ) did not generate significant neuronal depolarization when compared to the PBS control (mean $1.10 \mathrm{mV}$, SEM $0.22 \mathrm{mV}, \mathrm{N}=8, \mathrm{p} \leq 0.001$, One-way ANOVA, Tukey's post hoc test, Fig. 4C, E, F). Both the total $\mathrm{E} / \mathrm{S}$ and the $\mathrm{E} / \mathrm{S}$ products $<3 \mathrm{kDa}$ evoked a depolarization larger than that of the $\mathrm{E} / \mathrm{S}$ products $>3 \mathrm{kDa}(\mathrm{p} \leq 0.001$, One-way ANOVA, Tukey's post hoc test, Fig. 4A, B, D, F). Together this set of experiments demonstrated that $T$. crassiceps E/S products also contain an excitatory component, which is a small molecule.

Taenia crassiceps homogenate induced neuronal depolarization is not mediated by nicotinic acetylcholine receptors, ASIC receptors, or Substance P.

Our results demonstrate that the $T$. crassiceps derived small molecule induces neuronal depolarization very rapidly (within $\mathrm{ms}$ ), as such, it is highly likely that this molecule is an agonist of a neuronal ionotropic receptor. Therefore, we utilized pharmacological methods to determine the ionotropic receptor system via which the $T$. crassiceps derived small molecule acts.

Nicotinic acetylcholine receptors (nAchRs) are well described ionotropic receptors in the nervous system, which mediate depolarization via a mixed $\mathrm{Na}^{+}, \mathrm{K}^{+}$conductance (19). Again, using a caesium based internal solution in the presence of TTX in the aCSF, CA3 neurons were whole-cell patched and the peak voltage during $T$. crassiceps homogenate induced neuronal depolarisation measured before, during and after bath application of the non-competitive nicotinic acetylcholine receptor antagonist mecamylamine hydrochloride $(10 \mu \mathrm{M})$ to block nAchRs (Fig. 5A). The blockade of nAchRs did not significantly alter the $T$. crassiceps homogenate induced depolarisation. The median $T$. crassiceps homogenate induced depolarization was $16.28 \mathrm{mV}$ (IQR 13.54 - $23.63 \mathrm{mV}$ ) during baseline, $16.58 \mathrm{mV}$ 
(IQR $11.21-24.50 \mathrm{mV}$ ) in the presence of mecamylamine hydrochloride and $13.20 \mathrm{mV}$ (IQR $=10.37$ -

$23.48 \mathrm{mV}$ ) following washout ( $N=5, p=0.6914$, Friedman test, Fig. 5A,B).

356

357 Acid-sensing ion channels (ASICs) are proton-gated sodium channels known to be expressed by

hippocampal neurons and result in neuronal depolarization when activated. We therefore considered

that the $\mathrm{pH}$ of the $T$. crassiceps homogenate may be important as acidic conditions could activate activation of ASICs could underlie T. crassiceps homogenate induced depolarization we used the nonspecific ASIC blocker amiloride (2 $\mathrm{mM})$. The presence of amiloride did not significantly attenuate the effect of the homogenate (Fig. 5C), with the mean T. crassiceps homogenate induced depolarization being $14.55 \mathrm{mV}$ (SEM $1.41 \mathrm{mV}$ ) during baseline and $12.12 \mathrm{mV}$ (SEM $2.25 \mathrm{mV}$ ) in the presence of amiloride, whilst $17.06 \mathrm{mV}$ (SEM $2.20 \mathrm{mV}$ ) following washout $(\mathrm{N}=10, \mathrm{p}=0.1124$, repeated measures ANOVA, Fig. 5C, D).

A further possible candidate for our excitatory small molecule was Substance $P$, an abundant neuropeptide and neurotransmitter $(22,23)$. Robinson et al $(2012)$ have found Substance P in close vicinity to human NCC granulomas. Garza et al. (2010) found that substance P signalling contributes to granuloma formation and Substance P enhanced NMDA channel function (25). We therefore investigated whether Substance P could elicit a similar neuronal depolarizing response to that of $T$. crassiceps homogenate. However, we found that $100 \mu \mathrm{M}$ Substance $\mathrm{P}$ had no acute effect on the membrane potential of CA3 hippocampal pyramidal neurons (median $=0.08 \mathrm{mV}$, IQR $0.01-0.12 \mathrm{mV}$, $N=5$, Wilcoxon signed rank test with theoretical median $=0.00, p=0.0625$, Fig. 5E, F). Together these data indicate that $T$. crassiceps homogenate induced neuronal depolarization is not mediated by nicotinic acetylcholine receptors, ASIC receptors, nor by substance P. 
The depolarizing effects of Taenia crassiceps are mediated by glutamate receptor activation.

The predominant excitatory neurotransmitter in the nervous system is glutamate (19). Glutamate acid (in the aCSF) to block all three classes of GluRs. We found that GluR blockade significantly reduced $15.68 \mathrm{mV}$ ) to $1.90 \mathrm{mV}$ (IQR $1.09-2.21 \mathrm{mV}, \mathrm{N}=9, \mathrm{p} \leq 0.01$, Friedman test with Dunn's multiple comparison test, Fig. 6A, B), which recovered to a median value of $14.37 \mathrm{mV}$ (IQR $7.32-16.38 \mathrm{mV}$ ) following washout ( $N=9, p \leq 0.01$, Friedman test with Dunn's multiple comparison test, Fig. 6A, B). This indicated that activation of GluRs is the primary mediator of the depolarizing effect of $T$. crassiceps homogenate we observed.

Thereafter, we confirmed whether the depolarizing effect of $T$. crassiceps $E / S$ products is also mediated by GluRs. Here, too, we found that application of GluR antagonists reduced the median total (IQR $1.67-4.16 \mathrm{mV}, \mathrm{N}=10, \mathrm{p} \leq 0.01$, Friedman test with Dunn's multiple comparison test, Fig. 6C, D), which recovered to a median value of $16.43 \mathrm{mV}$ (IQR $14.41-23.14 \mathrm{mV}$ ) following washout $(\mathrm{N}=10$, $p \leq 0.01$, Friedman test with Dunn's multiple comparison test, Fig. 6C, D). These results indicate that the acute excitatory effect of both $T$. crassiceps homogenate and $T$. crassiceps $\mathrm{E} / \mathrm{S}$ products is mediated through GluRs. 

humans. We therefore also measured the glutamate concentration in homogenate prepared from larvae of $T$. solium, the predominant pathogen responsible for human NCC. We recorded a glutamate concentration of $4.56 \mu \mathrm{g} / \mathrm{mg}(\mathrm{N}=1)$, which indicates that the concentration of this excitatory neurotransmitter is also high within larvae of T. solium (Fig. 7A).

Whilst glutamate is a neurotransmitter in the CNS, it is also an ubiquitous metabolite present in the cytoplasm of the majority of cells (26). Therefore, it is possible that the T. crassiceps and T. solium homogenate only contain glutamate due to cell lysis during homogenate preparation. To determine whether both these larvae actively produce and excrete/secrete glutamate into their environments we measured the de novo daily production of glutamate by larvae following harvest of live larvae from the intermediate host (mice for T. crassiceps and pigs for T. solium, see Materials and Methods). Both species of larvae were observed to generate glutamate de novo and release this into the culture media

(Fig. 7B). T. crassiceps larvae released a relatively constant daily amount of glutamate (mean 64.07 $\mu \mathrm{g} / 15$ larvae per day, SEM $4.31 \mu \mathrm{g} / 15$ larvae per day, N = 3, Fig. 7B). T. solium larvae released a large amount of glutamate on the first day post-harvest, none on the $2^{\text {nd }}$ and $3^{\text {rd }}$ day in vitro, but again begin to produce large amounts of glutamate on days 4, 5 and 6 (mean $137.06 \mu \mathrm{g} / 15$ larvae per day, SEM 
bioRxiv preprint doi: https://doi.org/10.1101/859009; this version posted November 28, 2019. The copyright holder for this preprint (which was not certified by peer review) is the author/funder, who has granted bioRxiv a license to display the preprint in perpetuity. It is made available under aCC-BY 4.0 International license.

$431 T$. crassiceps and $T$. solium contain and continually release glutamate into their immediate

432 surroundings.

433 
Here we used patch-clamp electrophysiology, and calcium imaging in hippocampal organotypic brain slice cultures to demonstrate that Taenia larval products cause neuronal depolarization and can initiate seizure-like events via glutamate receptor activation. Glutamate assays revealed that both $T$. crassiceps and $T$. solium larvae contain and release considerable quantities of glutamate.

Clinical evidence and animal models conclusively demonstrate that the presence of larvae in the brain can result in the generation of seizures $(9,27)$. Previous work has focused on the involvement of the host inflammatory response in seizure generation $(10,28)$. Whilst this is likely important, it does not preclude the involvement of additional or exacerbating pathogenic mechanisms for seizure generation and epileptogenesis in NCC. In this study we have identified that Taenia larvae have a direct excitatory effect on neurons via glutamatergic signaling. This is important, as the central role of

31), slice (32-34), and in vivo models of epilepsy (35-37).

Clinically, in addition to NCC, the other major causes of adult acquired epilepsy are stroke, traumatic signaling and glutamate excitotoxicity are thought to be central to the pathogenic process. Glutamate excitotoxicity occurs when depolarized, damaged or dying neurons release glutamate, which activate surrounding neurons via NMDA and AMPA receptors, resulting in sustained neuronal depolarization, $\mathrm{Ca}^{2+}$ influx and the subsequent activation of signaling cascades and enzymes. These in turn lead to cell death via necrosis and apoptosis (40), the further release of intracellular glutamate and the propagation of the excitotoxic process to neighboring cells. In the neurons that survive, the prolonged exposure to glutamate has been shown to cause hyperexcitability and seizures $(29,31)$ via multiple 
quantities of glutamate, it is possible that should homeostatic mechanisms for taking up and metabolizing glutamate fail to compensate for larval-derived glutamate in the extracellular space, similar glutamate-dependent excitotoxic and epileptogenic processes that occur in stroke, traumatic brain injury and CNS tumors are likely to also occur in NCC.

Glioma, a common adult primary brain tumor, which typically presents with seizures in over $80 \%$ of

been shown to release glutamate into the extracellular space via the system $x_{c}{ }^{-}$cystine-glutamate antiporter (43). Interestingly, there is compelling evidence that tumoral release of glutamate via this mechanism both causes seizures and favours glioma preservation, progression and invasion in cases of malignant glioma (45-47). Analogously it is possible that Taenia larvae in the brain utilize the release of glutamate and the induction of glutamate excitotoxicity to facilitate their growth and expansion, with the accompanying effect of seizure generation. In addition, the death of Taenia larvae, or larval-derived cells would also result in the release of metabolic glutamate, further contributing to glutamate release and excitotoxicity. In the case of glioma, where the mechanism of glutamate release by tumor cells is known, pharmacological agents (e.g. sulfasalazine), which block glutamate release have considerable potential as therapeutic agents for reducing seizure burden in this condition. Therefore, it is important that future work attempts to identify the molecular mechanisms underlying the Taenia-specific production of glutamate in order to inform the development of new therapeutic strategies to potentially reduce larval expansion and treat seizures in NCC.

An important consideration is how we might reconcile our findings of continuous glutamate release experience acute seizures immediately following infection whilst others present with seizures months 
mechanisms might be involved in the epileptogenic process in NCC. Neuroinflammation has long been are optimized to maintain extracellular glutamate at low concentrations (50). However, the inflammatory transition of astrocytes to a reactive phenotype is known to impede their ability to buffer extracellular uptake (51). It is therefore conceivable that cyst-associated reactive astrocytosis may gradually erode the ability of homeostatic mechanisms to compensate for larvae derived extracellular glutamate resulting in delayed symptom onset in NCC.

497 It is clear that there is still considerable uncertainty regarding the precise sequences of events leading to seizure onset in NCC. Nonetheless our findings provide the first evidence that as is the case with the other common causes of adult acquired epilepsy (i.e. stoke, traumatic brain injury and glioma), increased extracellular, parasite-derived glutamate likely also plays an important role in the development of seizures in NCC. 

effect on the neuronal membrane potential (right, blue arrow), showing that potential mechanical disruption of the cell by a puff is not sufficient to depolarise it. C) As in 'B', identical effects of $T$. crassiceps homogenate could be elicited in current clamp recordings from a CA3 hippocampal pyramidal neuron in a mouse organotypic brain slice culture. D) Top: widefield fluorescence image of neurons in the dentate gyrus of a mouse hippocampal organotypic brain slice culture expressing the genetically-encoded $\mathrm{Ca}^{2+}$ reporter GCAMP6s under the synapsin promoter in aCSF containing $0.5 \mathrm{mM}$ $\mathrm{Mg}^{2+}$. A subset of neurons used to generate the $\mathrm{Ca}^{2+}$ traces in ' $\mathrm{E}$ ' are indicated by different colours. The orange dotted circle indicates where $T$. crassiceps homogenate was delivered using the puff pipette. Bottom, schematic of the experimental setup including puffer pipette and CCD camera for expressing neurons labelled in ' $D$ ' concurrent with 3 puffs (30 ms duration) of $T$. crassiceps homogenate $15 \mathrm{~s}$ apart. Bottom: two images of raw $\mathrm{Ca}^{2+}$ fluorescence at two time points $\mathrm{t}_{1}$ and $\mathrm{t}_{2}$.

524 Note how at time point $t_{2}$ neurons distant to the site of $T$. crassiceps homogenate application are also activated, indicating spread of neuronal activity. Inset, top-right: current clamp recording from a neuron demonstrates that $T$. crassiceps homogenate application was able to evoke a seizure-like event. 
Whole-cell patch clamp recording using a standard internal in current clamp mode from a CA3 caesium internal). Values with means $\pm \mathrm{SEM} ; * * * \mathrm{p} \leq 0.001$

molecule. Whole-cell patch recordings in current clamp mode were made from CA3 pyramidal neurons in rat organotypic hippocampal slice cultures using a caesium based internal in the presence of $2 \mu \mathrm{M}$ TTX. A) Delivery of a puff of $T$. crassiceps homogenate caused a depolarizing shift in membrane potential. B) The depolarizing response to $T$. crassiceps homogenate was largely abolished by dialysing out all molecules smaller than $3 \mathrm{kDa}$. C) Population data demonstrating that the $T$. crassiceps homogenate response is significantly reduced by dialysis, indicating that the excitatory component is a small molecule $(<3 \mathrm{kDa})$. Values with means $\pm \mathrm{SEM} ; * * * \mathrm{p} \leq 0.001$. clamp, whole-cell patch recording from a rat CA3 pyramidal neuron using a caesium based internal and $2 \mu \mathrm{M}$ TTX in the aCSF. A $20 \mathrm{~ms}$ puff of $T$. crassiceps excretory/secreted (E/S) products caused a marked depolarizing shift in voltage. B) Similar application of $T$. crassiceps $\mathrm{E} / \mathrm{S}$ products smaller than 
larger than $3 \mathrm{kDa}$ resulted in a negligible shift in membrane potential. D) No change in membrane voltage occurred in response to a puff of growth media, a control for the E/S products $<3 \mathrm{kDa}$. E) A negligible depolarization of the membrane voltage occurred in response to a puff of phosphatebuffered saline (PBS), a control for the E/S products $>3 \mathrm{kDa}$. F) Population data demonstrating that $T$. crassiceps $\mathrm{E} / \mathrm{S}$ products as a whole or when separated to $\mathrm{E} / \mathrm{S}$ products $<3 \mathrm{kDa}$ cause significant depolarization when compared to either the larger constituent of $E / S$ products or either of the control substances. Values with means \pm SEM; ${ }^{* * *} p \leq 0.001 ; n s=$ not significant, $p>0.05$ nicotinic acetylcholine receptors, ASIC receptors, or Substance P. Whole-cell patch recordings were made from CA3 pyramidal neurons in rat organotypic hippocampal slice cultures using a caesium based internal in the presence of $2 \mu \mathrm{M}$ TTX. If necessary, current was injected to maintain the membrane potential within $2 \mathrm{mV}$ of $-60 \mathrm{mV}$. A) The depolarizing response to a $T$. crassiceps homogenate puff (orange arrow) before (black trace), during (blue trace) and after (grey trace) the

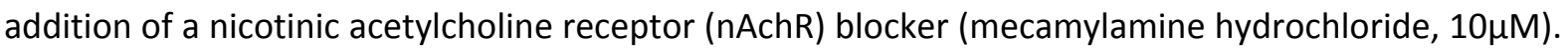
showing that a puff of $100 \mu \mathrm{M}$ Substance $\mathrm{P}$ (blue arrow) does not affect the membrane potential of CA3 pyramidal neurons. F) Population data for Substance $\mathrm{P}$ application. $\mathrm{ns}=$ not significant, $\mathrm{p}>0.05$. 
581 homogenate (orange arrow) before (black trace), during (blue trace) and following wash out (grey

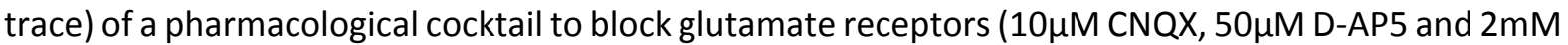
kynurenic acid). B) Population data shows that the depolarization response to $T$. crassiceps homogenate is significantly reduced in the presence of glutamate receptor blockers and returns upon reduced during glutamate receptor blockade. D) Population data for glutamate receptor blockade during $T$. crassiceps E/S products application. Values with means $\pm \mathrm{SEM} ; * * * \leq 0.001 ; * * p \leq 0.01$.

589 Figure 7: Taenia crassiceps and Taenia solium larvae contain and produce glutamate. A) Glutamate

590 levels in whole cyst hom. of $T$. crassiceps and $T$. solium larvae. B) Glutamate production per day per

59115 larvae for 6 days in vitro for T. crassiceps and T. solium larvae. Note that both species of larvae produce glutamate de novo, particularly on days $4-6$. 


\section{References}

1. Diop AG, Boer HM De, Mandlhate C, Prilipko L, Meinardi H. The global campaign against epilepsy in Africa. Acta Trop. 2003;87:149-59.

2. Preux P-M, Druet-Cabanac M. Epidemiology and aetiology of epilepsy in sub-Saharan Africa. Lancet Neurol. 2005 Jan;4(1):21-31.

3. Trevisan C, Mkupasi EM, Ngowi HA, Forkman B, Johansen M V. Severe seizures in pigs naturally infected with Taenia solium in Tanzania. Vet Parasitol. 2016;220:67-71.

4. Garcia HH, Del OH. Antiparasitic treatment of neurocysticercosis - The effect of cyst destruction in seizure evolution. Epilepsy Behav. 2017;76:158-62.

5. Nash TE, Mahanty S, Garcia HH. Neurocysticercosis-More Than a Neglected Disease. PLoS Negl Trop Dis. 2013;7(4):7-9.

6. Ndimubanzi PC, Carabin H, Budke CM, Nguyen H, Qian YJ, Rainwater E, et al. A systematic review of the frequency of neurocyticercosis with a focus on people with epilepsy. PLoS Negl Trop Dis. 2010;4(11).

7. de Lange A, Mahanty S, Raimondo J V. Model systems for investigating disease processes in neurocysticercosis. Parasitology. 2018 Nov 15;1-10.

8. Vezzani A, Fujinami RS, White HS, Preux P, Blümcke I, Sander JW, et al. Infections, inflammation and epilepsy. Acta Neuropathol. 2016;131:211-34.

9. Nash TE, Mahanty S, Loeb J a., Theodore WH, Friedman A, Sander JW, et al. Neurocysticercosis: A natural human model of epileptogenesis. Epilepsia. 2015 Feb;56(2):177-83.

10. Robinson P, Garza A, Weinstock J, Serpa J a, Goodman JC, Eckols KT, et al. Substance P causes seizures in neurocysticercosis. PLoS Pathog. 2012 Feb;8(2):e1002489.

11. Sun Y, Chauhan A, Sukumaran P, Sharma J, Singh BB, Mishra BB. Inhibition of store-operated calcium entry in microglia by helminth factors: implications for immune suppression in neurocysticercosis. J Neuroinflammation. 2014 Dec 24;11(1):210.

12. Vendelova E, Camargo de Lima J, Lorenzatto KR, Monteiro KM, Mueller T, Veepaschit J, et al. Proteomic Analysis of Excretory-Secretory Products of Mesocestoides corti Metacestodes Reveals Potential Suppressors of Dendritic Cell Functions. PLoS Negl Trop Dis. 2016;10(10):127.

13. Stoppini L, Buchs P-A, Muller D. A simple method for organotypic cultures of nervous tissue. J Neurosci Meth. 1991 Apr;37(2):173-182.

14. Forman CJ, Tomes H, Mbobo B, Baden T, Raimondo J V. Openspritzer: an open hardware pressure ejection system for reliably delivering picolitre volumes. bioRxiv. 2016;093633.

15. Edelstein A, Amodaj N, Hoover K, Vale R, Stuurman N. Computer Control of Microscopes Using $\mu$ Manager. In: Current Protocols in Molecular Biology. Hoboken, NJ, USA: John Wiley \& Sons, Inc.; 2010. p. 14.20.1-14.20.17.

16. Forman CJ, Tomes H, Mbobo B, Burman RJ, Jacobs M, Baden T, et al. Openspritzer: an open hardware pressure ejection system for reliably delivering picolitre volumes. Sci Rep. 2017 May;7(1):2188.

17. Jiang C, Haddad GG. Effect of anoxia on intracellular and extracellular potassium activity in hypoglossal neurons in vitro. J Neurophysiol. 1991;66(1):103-11.

18. Lesage F. Pharmacology of neuronal background potassium channels. Neuropharmacology. 2003;44:1-7. 
19. Bear MF, Connors BW, Paradiso MA. Neuroscience: Exploring the brain. Third. Lupash E, Connolly E, Dilernia B, Williams P, editors. Philadelphia, Baltimore, New York, London, Buenos Aires, Hong Kong, Sydney, Tokyo: Lippincott Williams \& Wilkins; 2007.

20. Weng X, Zheng J, Gai X, Li J, Xiao W. Two types of acid-sensing ion channel currents in rat hippocampal neurons. Neurosci Res. 2004;50:493-9.

21. Osmakov DI, Koshelev SG, Andreev YA, Kozlov SA. Endogenous isoquinoline alkaloids agonists of acid-sensing ion channel type 3. Front Mol Neurosci. 2017;10(September):1-7.

22. Liu H, Mazarati AM, Katsumori $H$, Sankar R, Wasterlain CG. Substance $P$ is expressed in hippocampal principal neurons during status epilepticus and plays a critical role in the maintenance of status epilepticus. Proc Natl Acad Sci. 2002;96(9):5286-91.

23. Harrison S, Geppetti P. Substance P. Int J Biochem Cell Biol. 2001;33(6):555-76.

24. Garza A, Tweardy DJ, Weinstock J, Viswanathan B, Robinson P. Substance P signaling contributes to granuloma formation in taenia crassiceps infection, a murine model of cysticercosis. J Biomed Biotechnol. 2010;2010.

25. Lieberman DN, Mody I. Substance P enhances NMDA channel function in hippocampal dentate gyms granule cells. J Neurophysiol. 1998;80(1):113-9.

26. Newsholme P, Procopio J, Ramos Lima MM, Pithon-Curi TC, Curi R. Glutamine and glutamatetheir central role in cell metabolism and function. Cell Biochem Funct. 2002;21:1-9.

27. Verastegui MR, Mejia A, Clark T, Gavidia CM, Mamani J, Ccopa F, et al. Novel Rat Model for Neurocysticercosis Using Taenia solium. Am J Pathol. 2015;185(8):2259-68.

28. Stringer JL, Marks LM, White AC, Robinson P. Epileptogenic activity of granulomas associated with murine cysticercosis. Exp Neurol. 2003 Oct;183(2):532-6.

29. Sun DA, Sombati S, DeLorenzo RJ. Glutamate Injury-Induced Epileptogenesis in Hippocampal Neurons. Stroke. 2001 Oct 1;32(10):2344-50.

30. Sombati S, Delorenzo RJ. Recurrent spontaneous seizure activity in hippocampal neuronal networks in culture. J Neurophysiol. 1995 Apr;73(4):1706-11.

31. DeLorenzo R, ... SP-P of the, 1998 undefined. Prolonged activation of the N-methyl-d-aspartate receptor-Ca2+ transduction pathway causes spontaneous recurrent epileptiform discharges in hippocampal neurons. Natl Acad Sci.

32. Anderson WW, Anderson WW, Lewis D V., Scott Swartzwelder H, Wilson WA. Magnesium-free medium activates seizure-like events in the rat hippocampal slice. Brain Res. 1986;398(1):2159.

33. Stasheff S, Anderson W, Clark S, Science WW-, 1989 undefined. NMDA antagonists differentiate epileptogenesis from seizure expression in an in vitro model. science.sciencemag.org.

34. Ziobro JM, Deshpande LS, DeLorenzo RJ. An organotypic hippocampal slice culture model of excitotoxic injury induced spontaneous recurrent epileptiform discharges. Brain Res. 2011 Jan 31;1371:110-20.

35. Croucher MJ, Bradford HF. NMDA receptor blockade inhibits glutamate-induced kindling of the rat amygdala. Brain Res. 1990;506(2):349-52.

36. Croucher MJ, Bradford HF, Sunter DC, Watkins JC. Inhibition of the development of electrical kindling of the prepyriform cortex by daily focal injections of excitatory amino acid antagonists. Eur J Pharmacol. 1988;152(1-2):29-38. 
37. Rice AC, Delorenzo RJ. NMDA receptor activation during status epilepticus is required for the development of epilepsy. Brain Res. 1998;782(1-2):240-7.

38. Hauser WA, Annegers JF, Kurland LT. Prevalence of Epilepsy in Rochester, Minnesota: 19401980. Epilepsia. 1991 Aug;32(4):429-45.

39. Forsgren L, Beghi E, Oun A, Sillanpaa M. The epidemiology of epilepsy in Europe - a systematic review. Eur J Neurol. 2005 Apr 1;12(4):245-53.

40. Ankarcrona M, Dypbukt JM, Bonfoco E, Zhivotovsky B, Orrenius S, Lipton SA, et al. Glutamateinduced neuronal death: A succession of necrosis or apoptosis depending on mitochondrial function. Neuron. 1995 Oct 1;15(4):961-73.

41. Lee HHC, Deeb TZ, Walker JA, Davies PA, Moss SJ. NMDA receptor activity downregulates KCC2 resulting in depolarizing GABAA receptor-mediated currents. Nat Neurosci. 2011 Jun 1;14(6):736-43.

42. Terunuma $M$, Vargas KJ, Wilkins ME, Ramírez OA, Jaureguiberry-Bravo $M$, Pangalos $M N$, et al. Prolonged activation of NMDA receptors promotes dephosphorylation and alters postendocytic sorting of GABAB receptors. Proc Natl Acad Sci. 2010 Aug 3;107(31):13918-23.

43. Buckingham SC, Campbell SL, Haas BR, Montana V, Robel S, Ogunrinu T, et al. Glutamate release by primary brain tumors induces epileptic activity. Nat Med. 2011 Oct 11;17(10):126974.

44. Santosh V, Sravya P. Glioma, glutamate (SLC7A11) and seizures-a commentary. Ann Transl Med. 2017 May;5(10):214.

45. Sontheimer H. A role for glutamate in growth and invasion of primary brain tumors. J Neurochem. 2008 Apr 1;105(2):287-95.

46. Takano T, Lin JH-C, Arcuino G, Gao Q, Yang J, Nedergaard M. Glutamate release promotes growth of malignant gliomas. Nat Med. 2001 Sep;7(9):1010-5.

47. Huang $W$, Choi $W$, Chen $Y$, Zhang $Q$, Deng $H$, He W, et al. A proposed role for glutamine in cancer cell growth through acid resistance. Cell Res. 2013 May 29;23(5):724-7.

48. Adalid-Peralta L, Arce-Sillas A, Fragoso G, Cárdenas G, Rosetti M, Casanova-Hernández D, et al. Cysticerci drive dendritic cells to promote in vitro and in vivo tregs differentiation. Clin Dev Immunol. 2013;2013:1-9.

49. Verma A, Prasad KN, Cheekatla SS, Nyati KK, Paliwal VK, Gupta RK. Immune response in symptomatic and asymptomatic neurocysticercosis. Med Microbiol Immunol. 2011 Nov $1 ; 200(4): 255-61$.

50. Perea G, Araque A. GLIA modulates synaptic transmission. Brain Res Revs. 2010 May;63(12):93-102.

51. Seifert G, Carmignoto G. Astrocyte dysfunction in epilepsy. Brain Res Rev. 2010 May 1;63(12):212-21. 
${ }^{A} g_{2}$

T. crassiceps

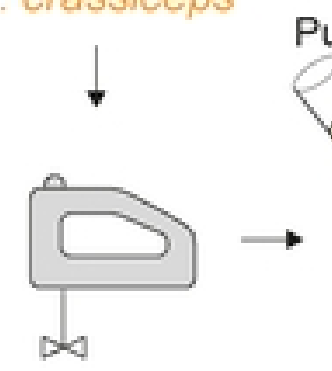

Homogenization

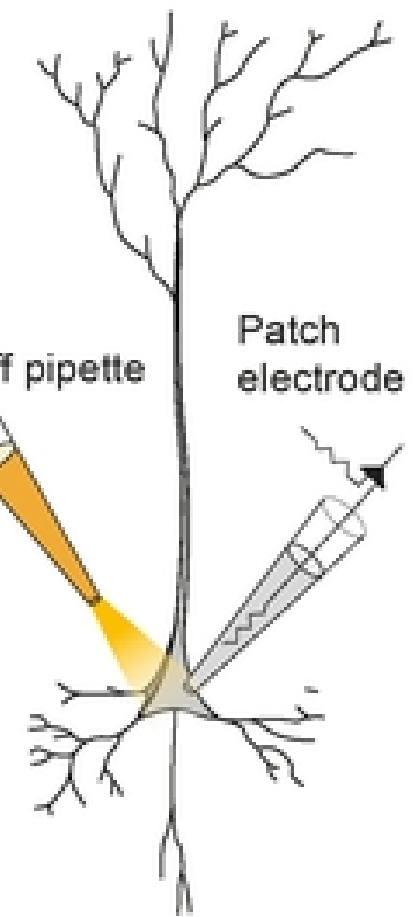

D
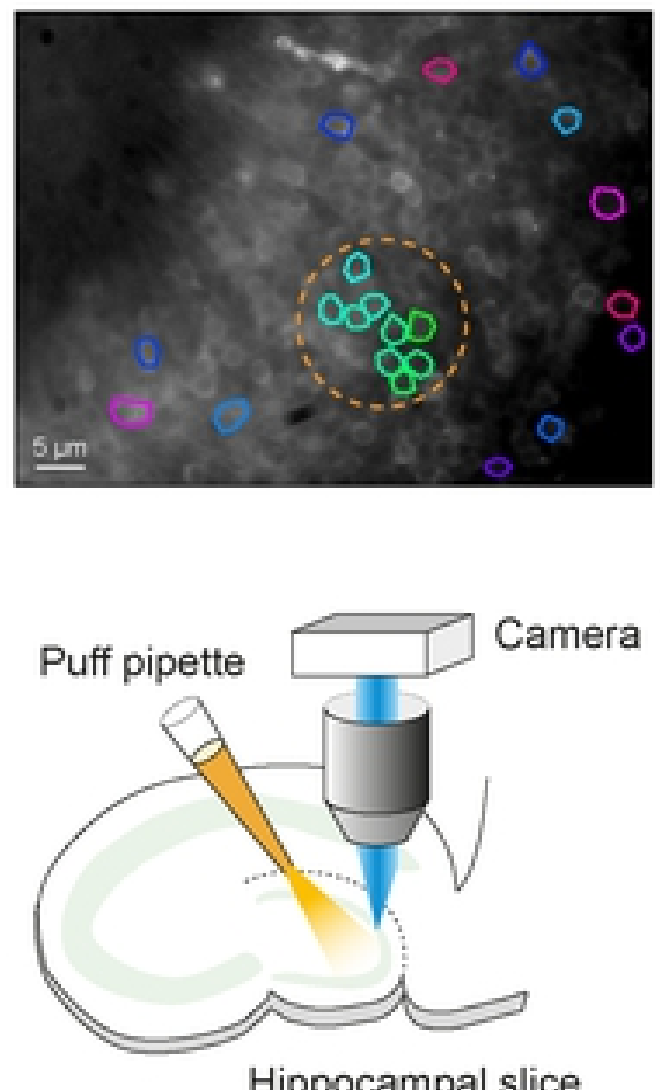

B $\begin{gathered}\text { T. crass. } \\ \text { hom. }\end{gathered}$

$-60 \mathrm{mV}$

C T. crass.
hom.

$-60 \mathrm{mV}$

E

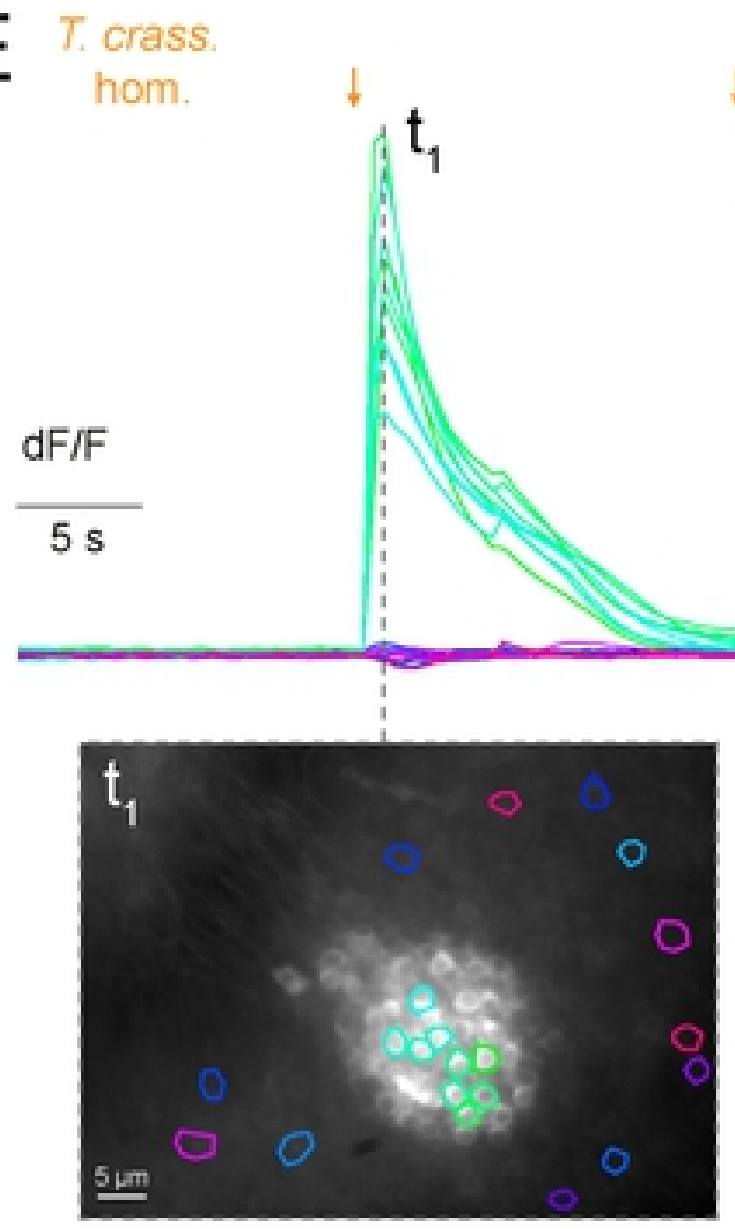

$a C S F \downarrow$

$20 \mathrm{mV} \underset{0.5 \mathrm{~s}}{\bigsqcup}$
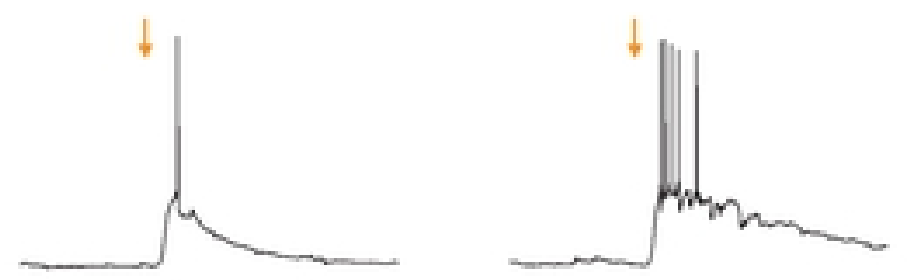

aCSF

$20 \mathrm{mV} \underset{0.5 \mathrm{~s}}{\lfloor}$

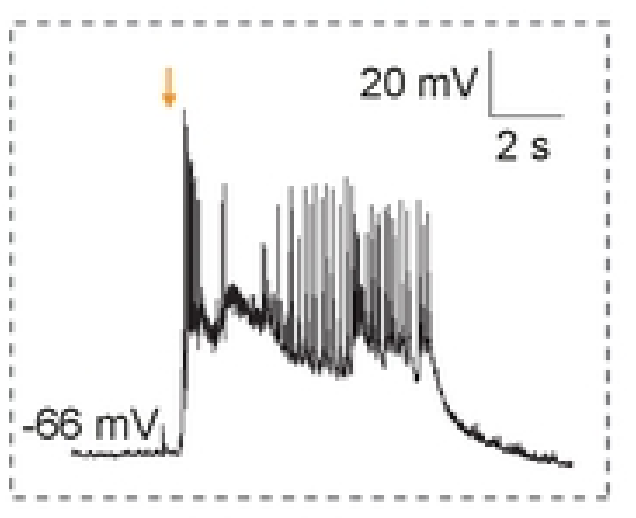

Figure 1: Taenia crassiceps homogenate excites neurons and can generate epileptiform activity

Figure 1 


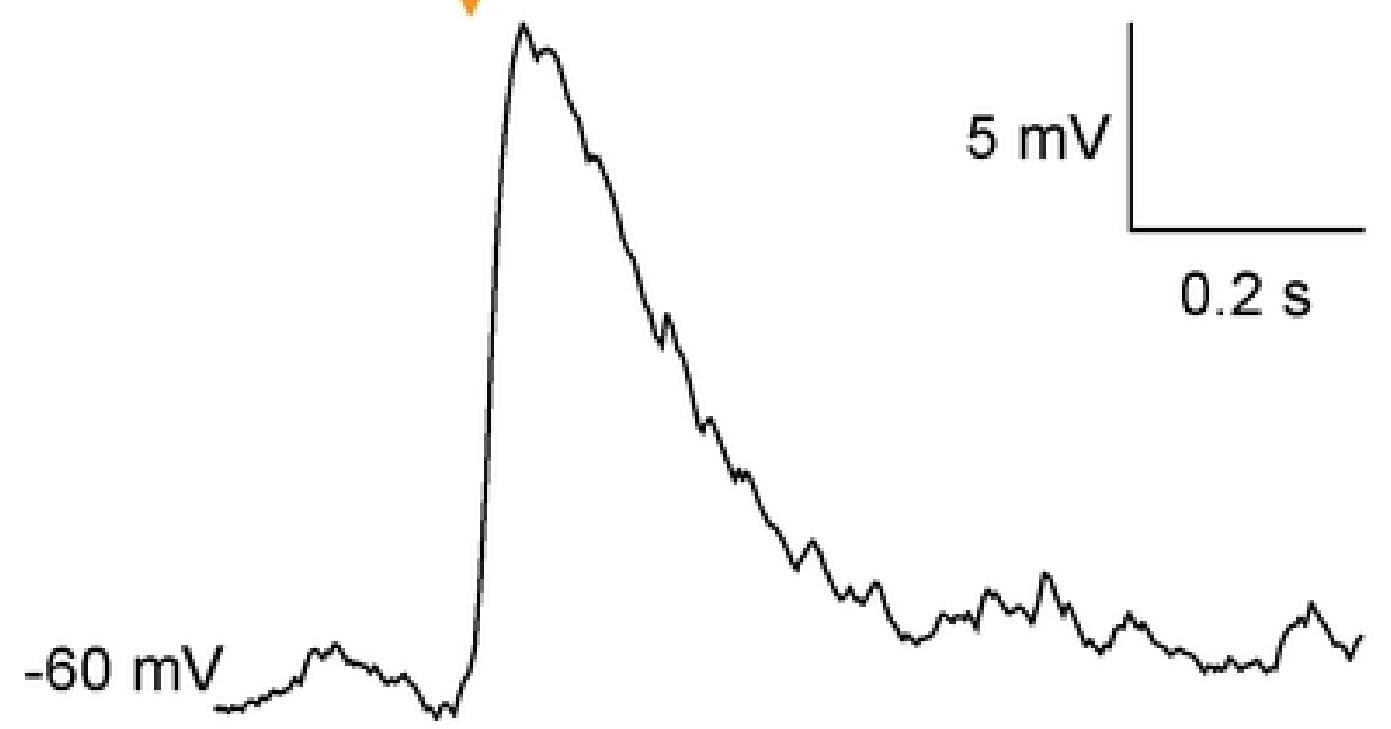

B

$11.39 \mathrm{mM} \mathrm{K}^{+}$

+ TTX

bioRxiv preprint doi: https://doi.org/10.1101/859009; this version posted November 28, 2019. The copyright holder for this preprint was not certified by peer review) is the author/funder, who has granted bioRxiv a license to display the preprint in perpetuity. It is

C available under aCC-BY 4.0 International license.

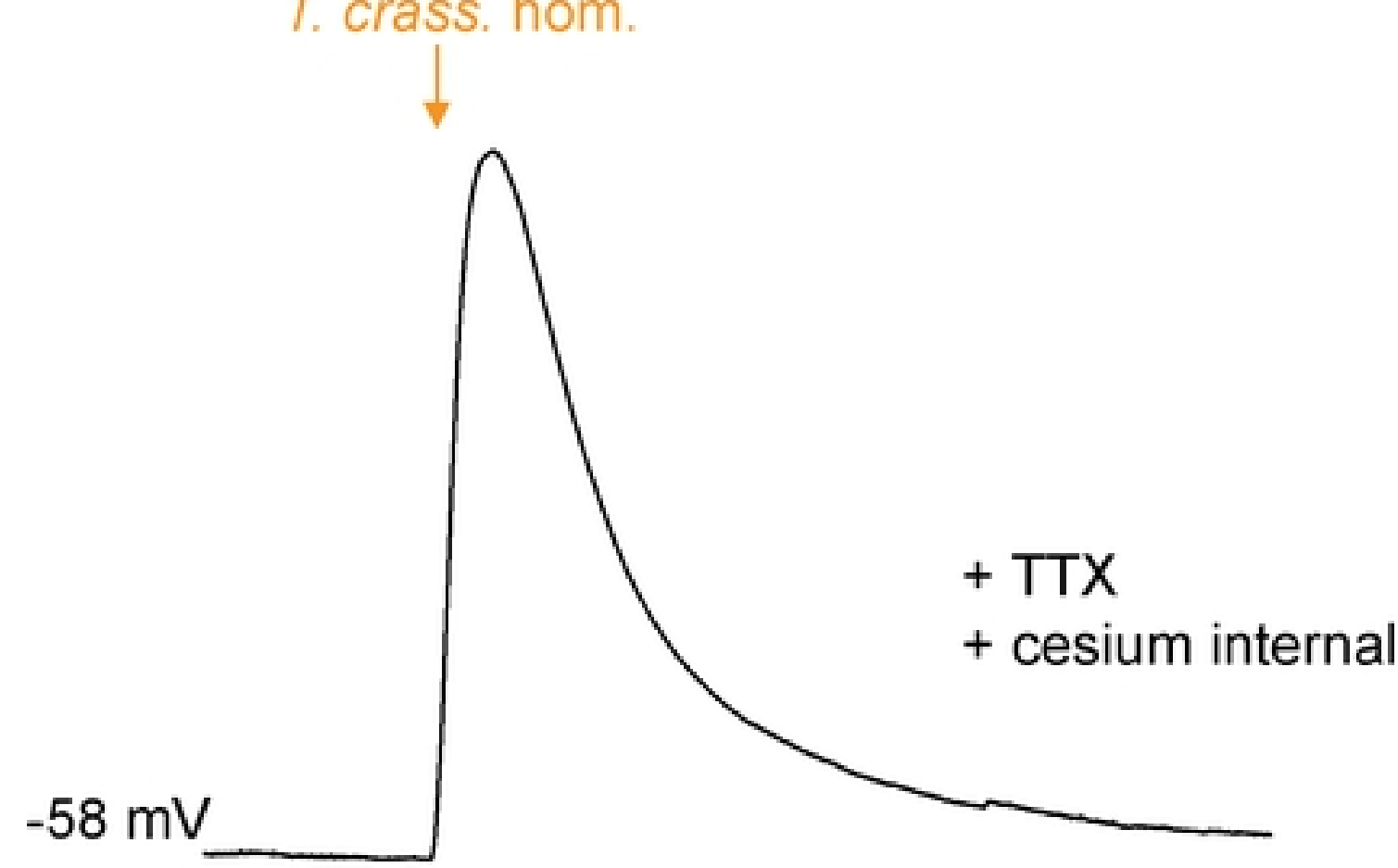

D

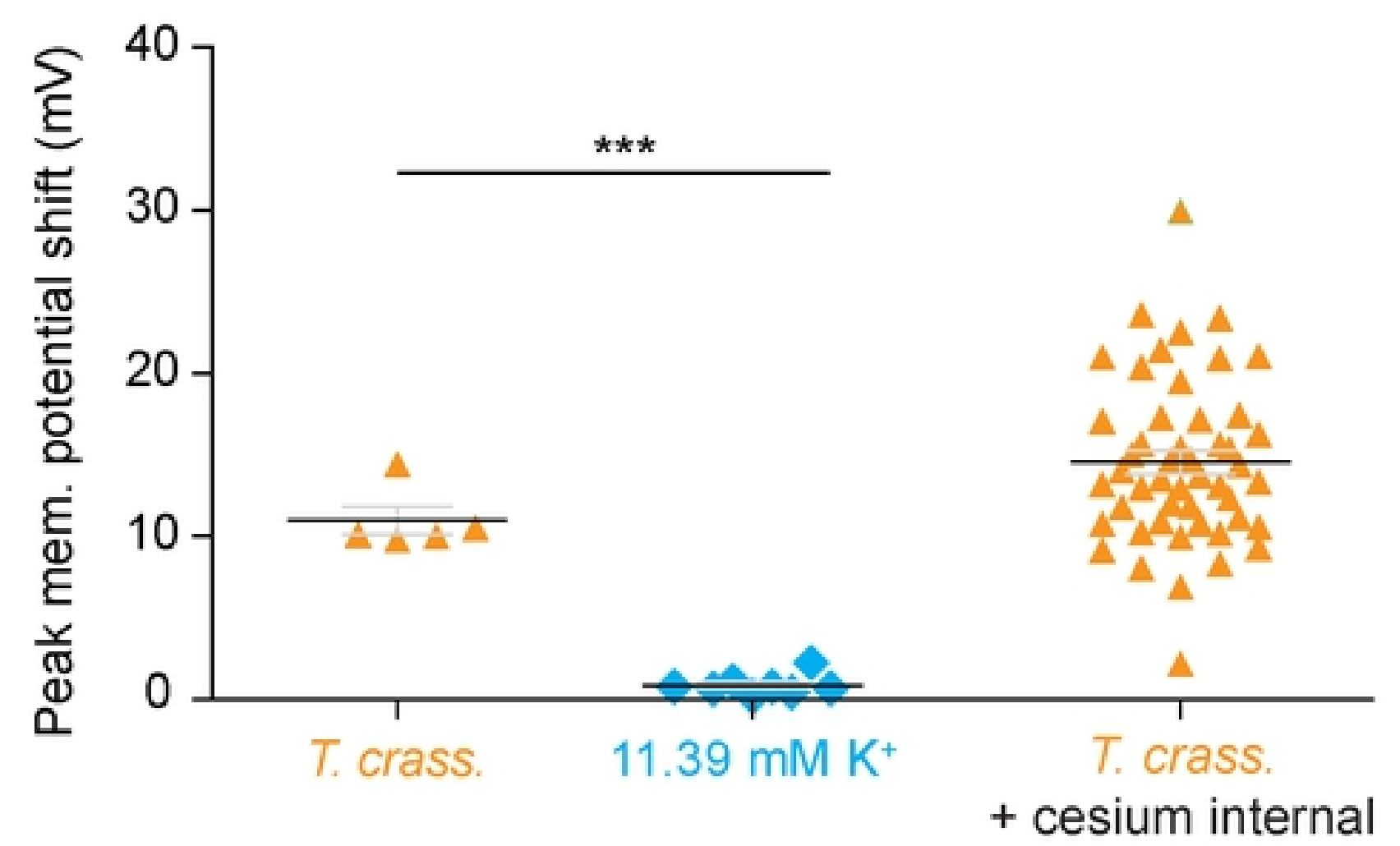

Figure 2: $\mathrm{K}^{+}$contributes modestly to Taenia crassiceps induced neuronal depolarization

Figure 2 
A t. crass. hom.

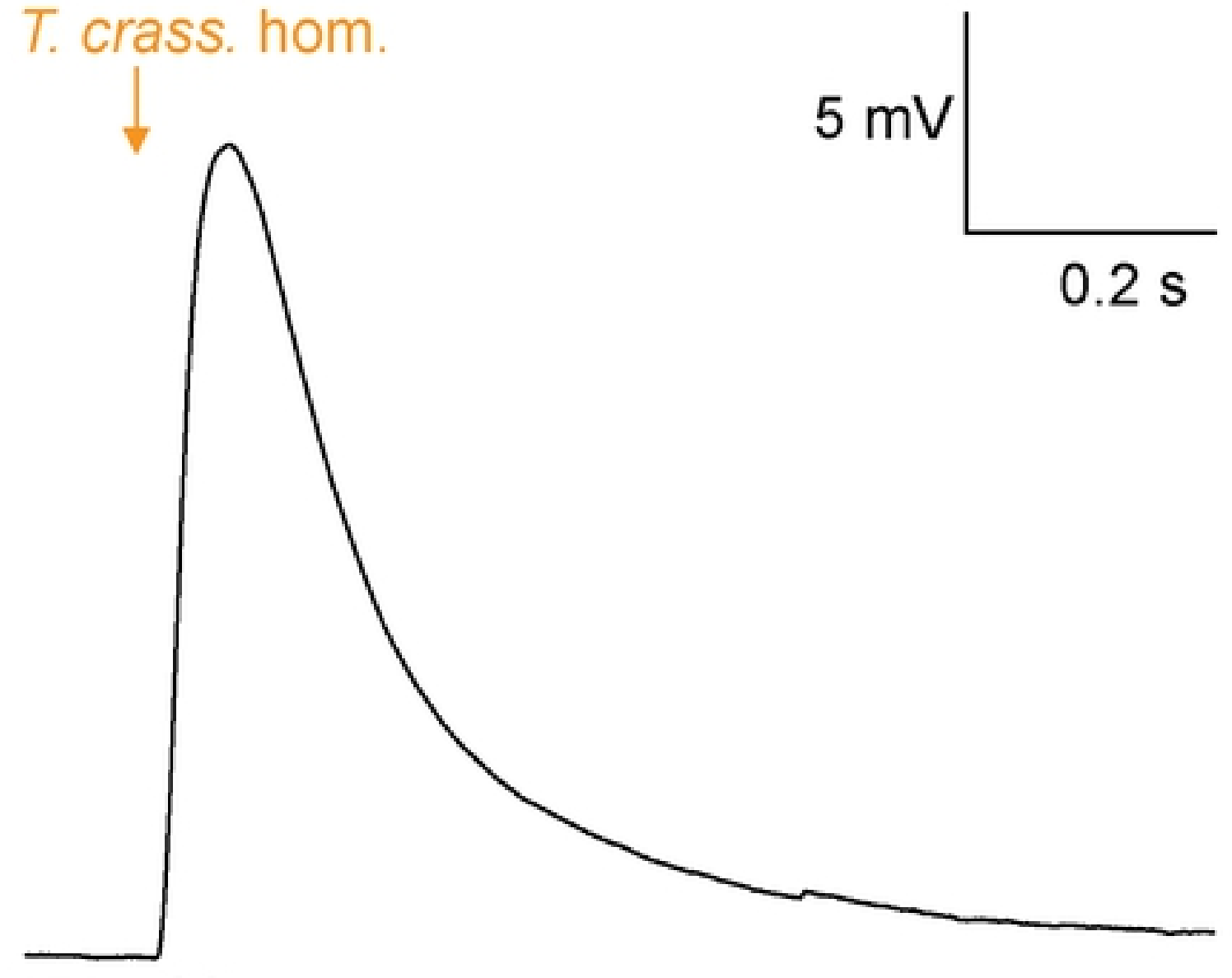

$-58 \mathrm{mV}$

bioRxiv preprint doi: https:/doi org/10.1101/859009: this version posted November 28, 2019. The copyright holder for this preprint (which

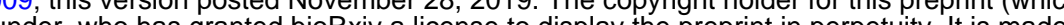

B

\section{T. crass. hom. (> $3 \mathrm{kDa})$ \\ $\downarrow$}

$-60 \mathrm{mV}$

C

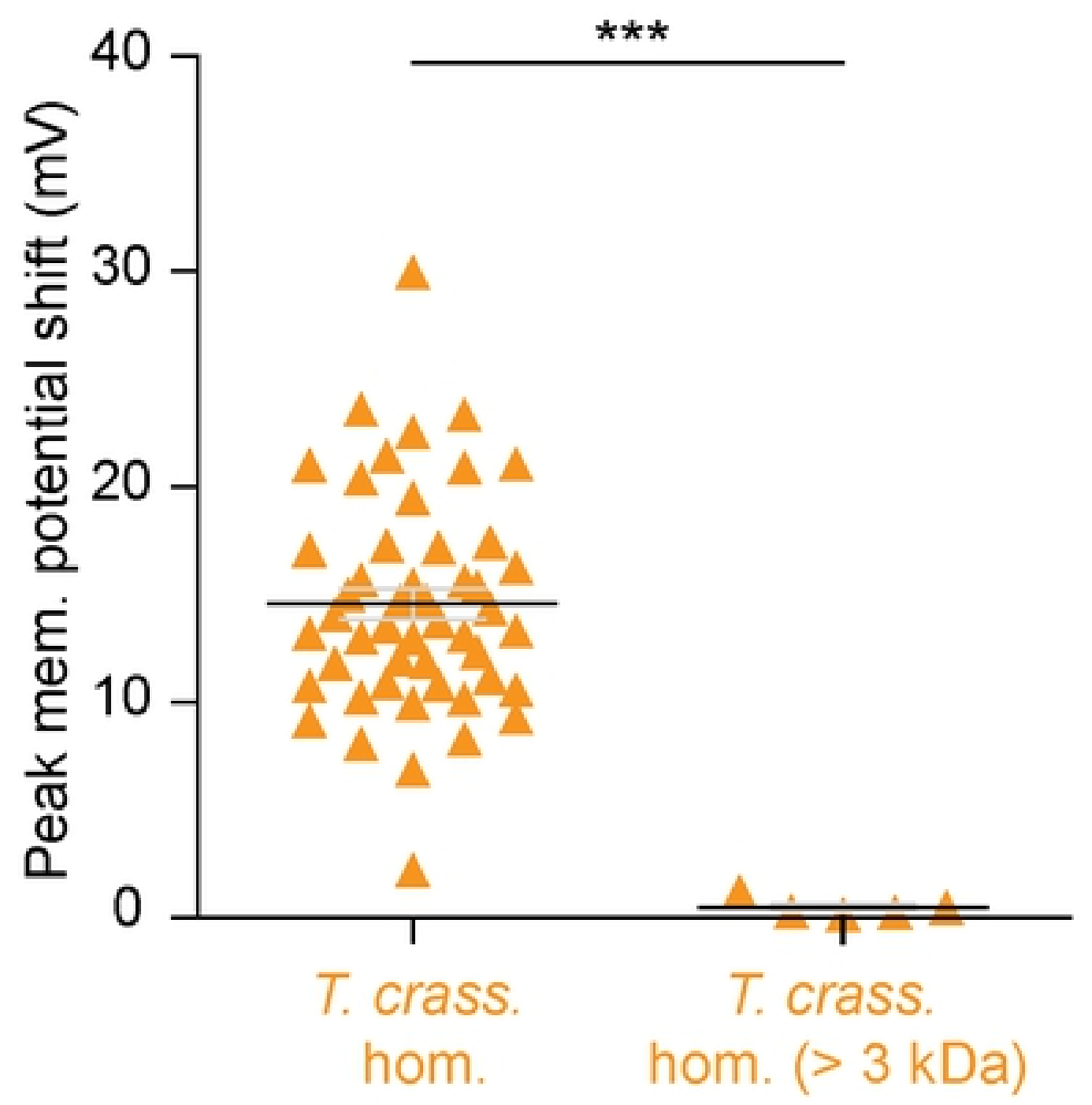

Figure 3: Taenia crassiceps homogenate induced neuronal depolarization is mediated by a small molecule

Figure 3 


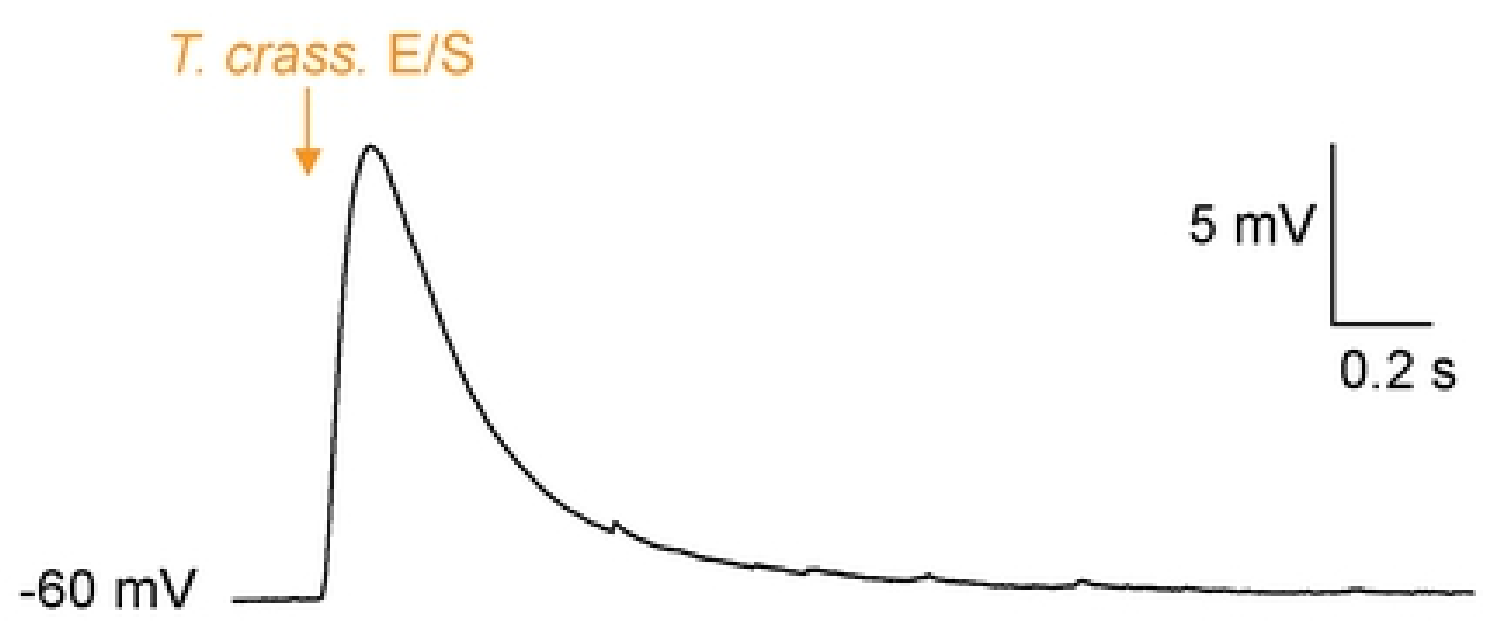

B

T. crass. E/S $(<3 \mathrm{kDa})$

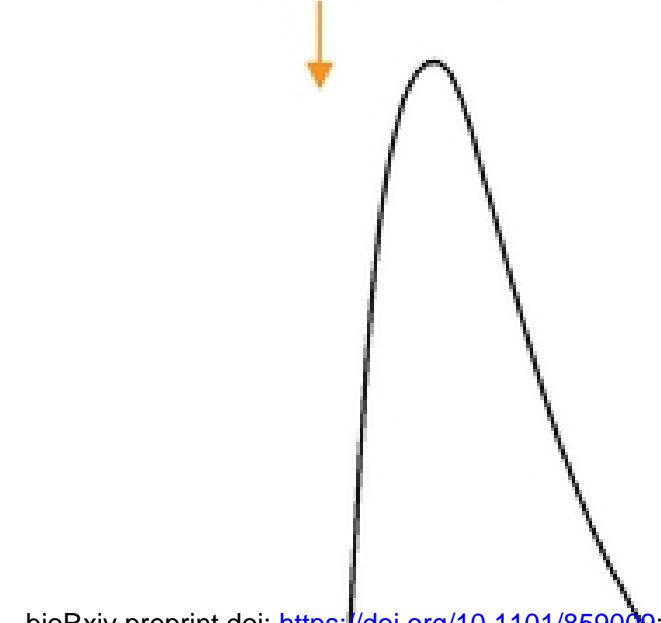

1/85900; this version posted November 28, 2019. The copyright holder for this prepr was not certified by peer (review) is the author/funder, who has granted bioRxiv a license to display the preprint in perpetuity. $-60 \mathrm{mV}$

C

T. crass. E/S (>3 kDa)

$\downarrow$

$-60 \mathrm{mV}$

D<smiles>C[C+]1CCCC1</smiles>

$-63 \mathrm{mV}$

E

PBS Ger aCC-BY 4.0 International license.

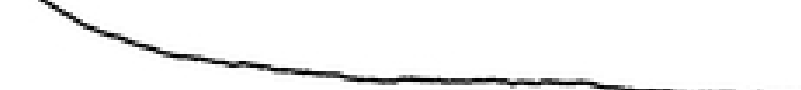


A T. crass. hom.

bioRxiv preprint doi: $h$ ttps://doi org/10 1101/859009. this version posted November 28,2019 . The copyright holder for this preprint (which was not certified by peer review) is the author/funder, who has granted bioRxiv a license to display the pepprin th perpetuity. It is made

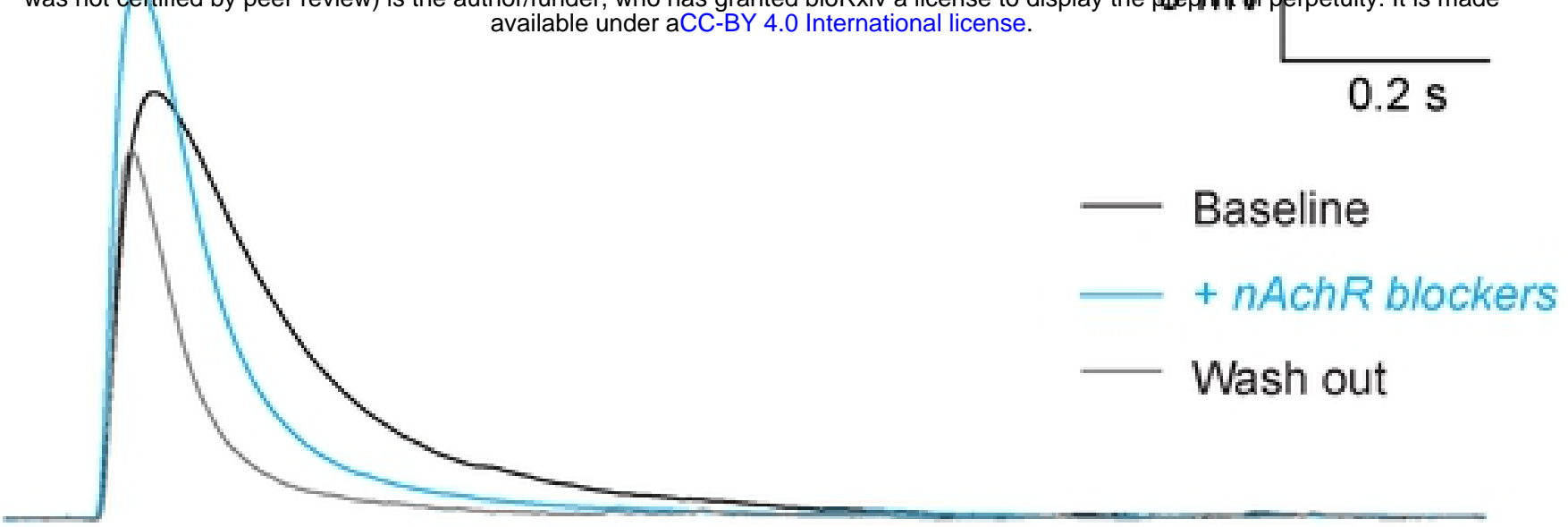

C

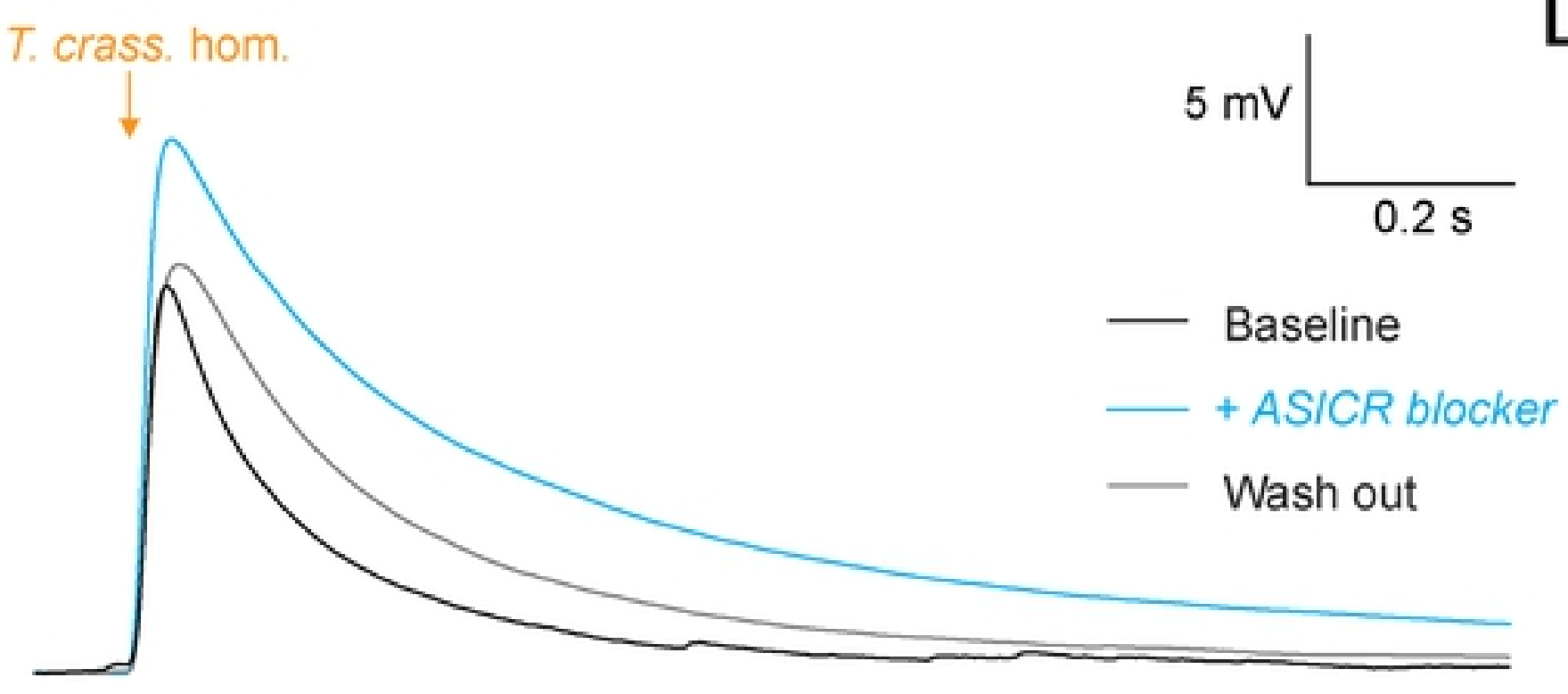

$\mathrm{E}$

Substance P

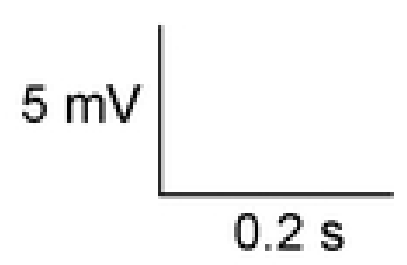

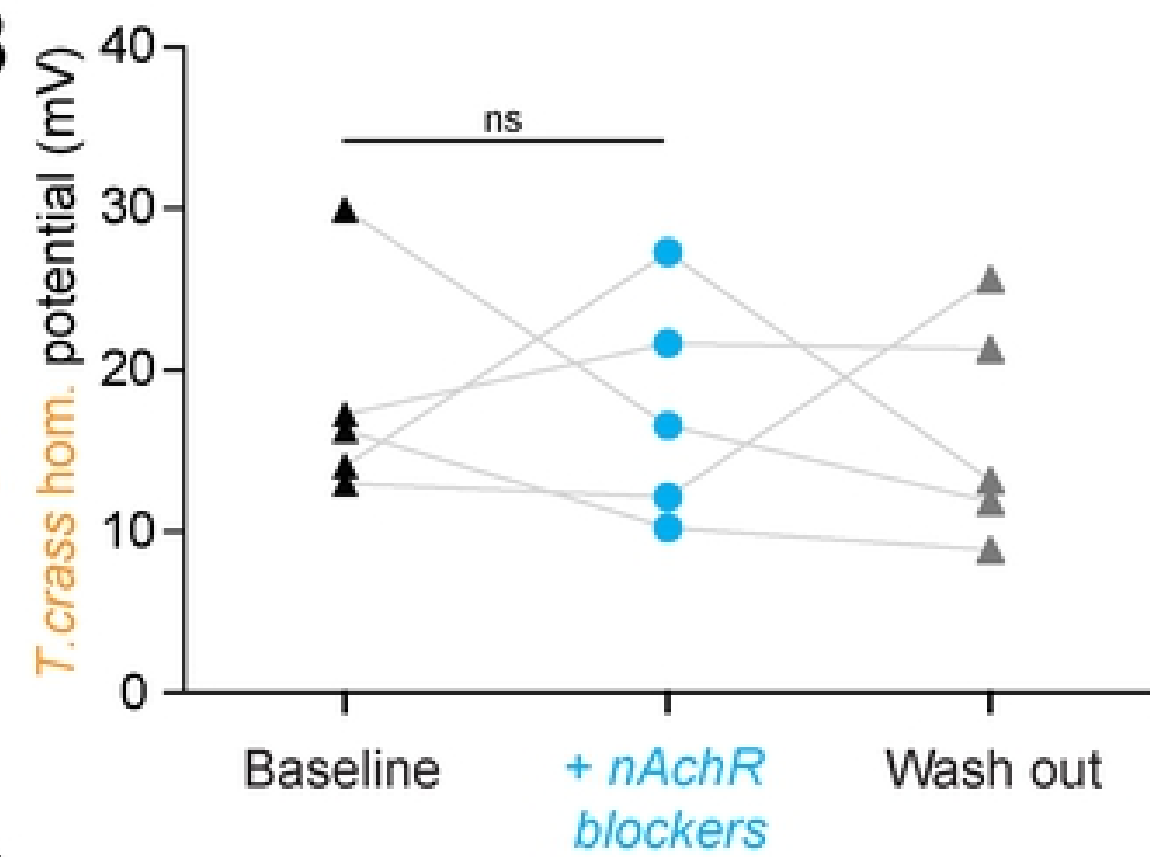

D

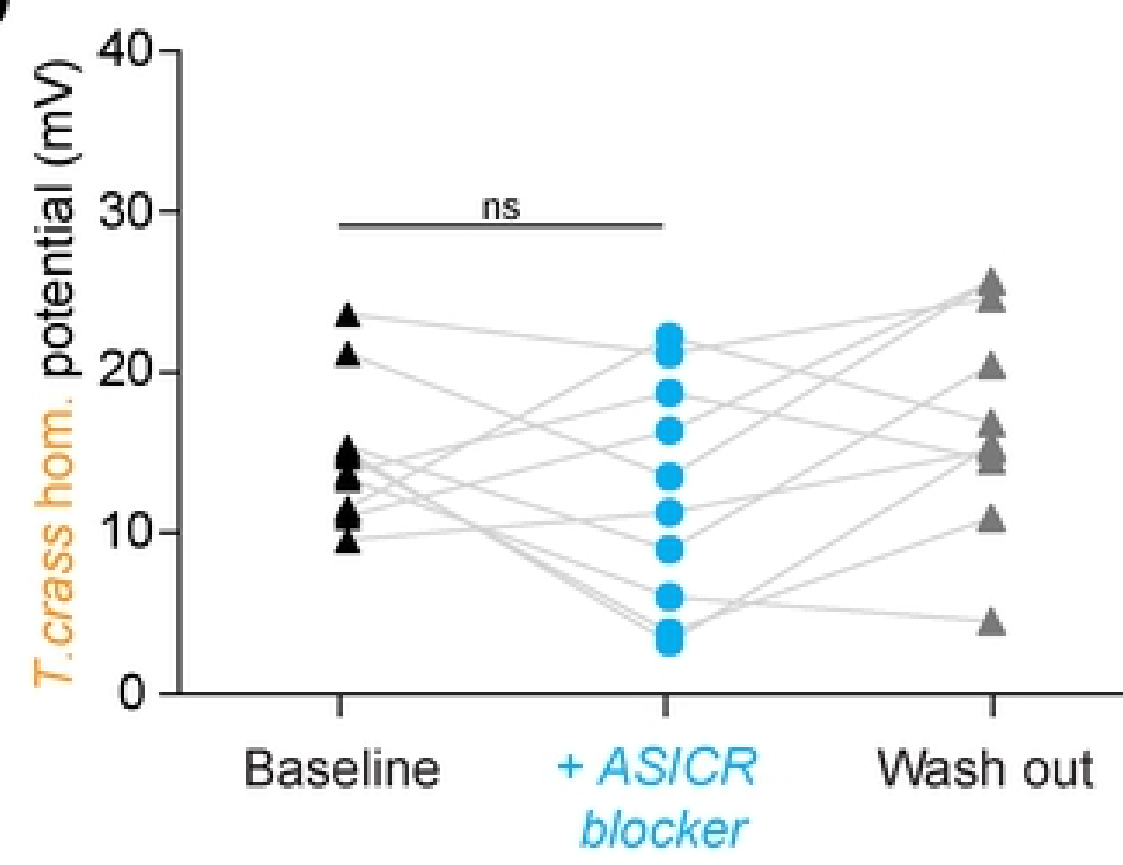

$\mathrm{F}$

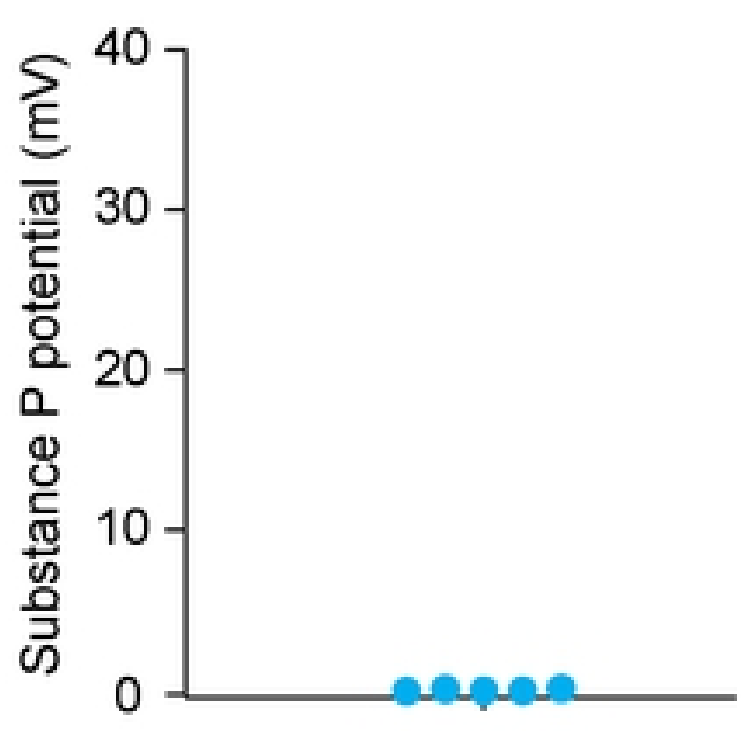

Figure 5: Taenia crassiceps homogenate induced neuronal depolarization is not mediated by acetylcholine receptors, ASIC receptors nor Substance $P$

Figure 5 
$A$

T. crass, hom.

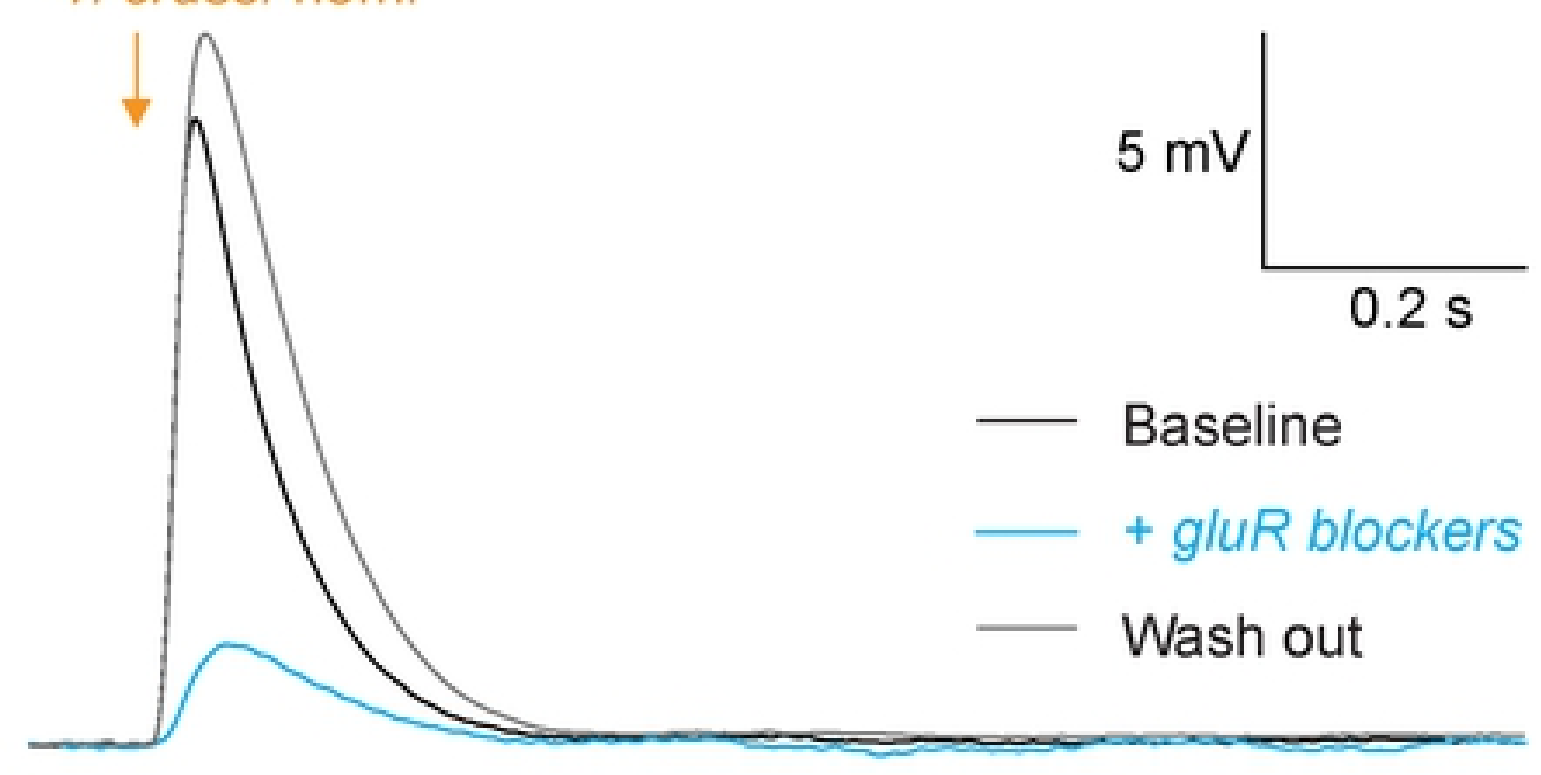

C

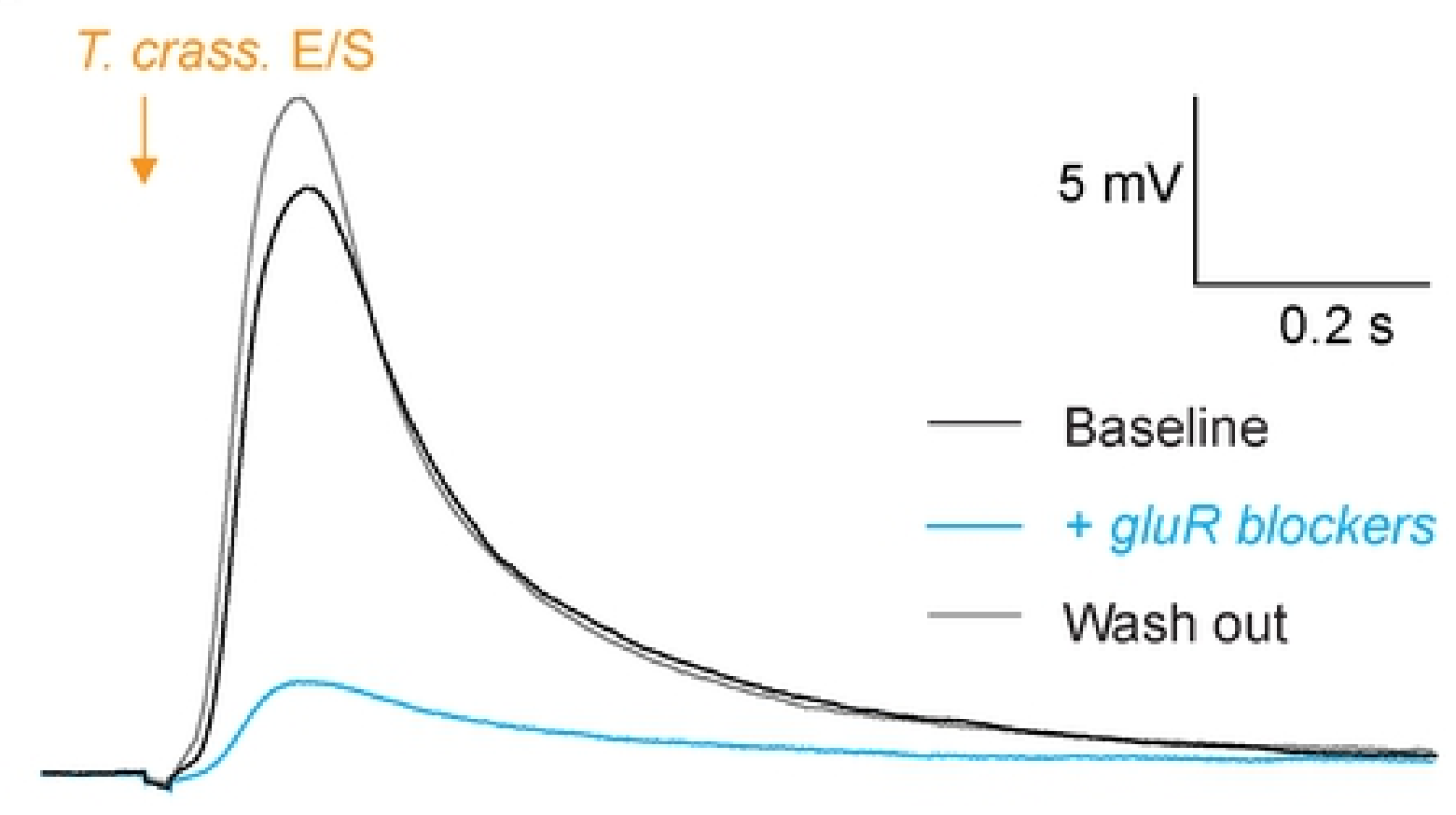

B

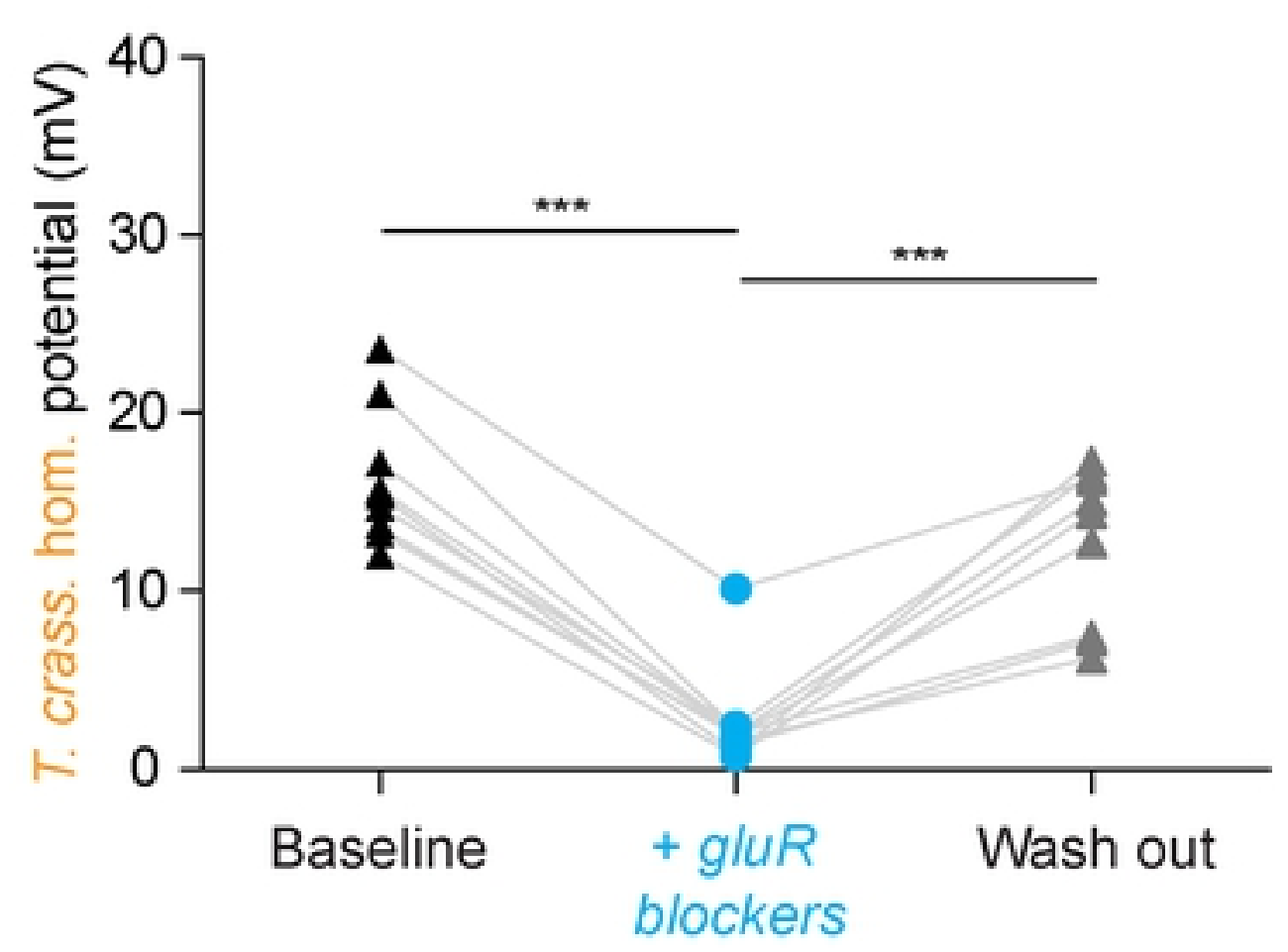

D

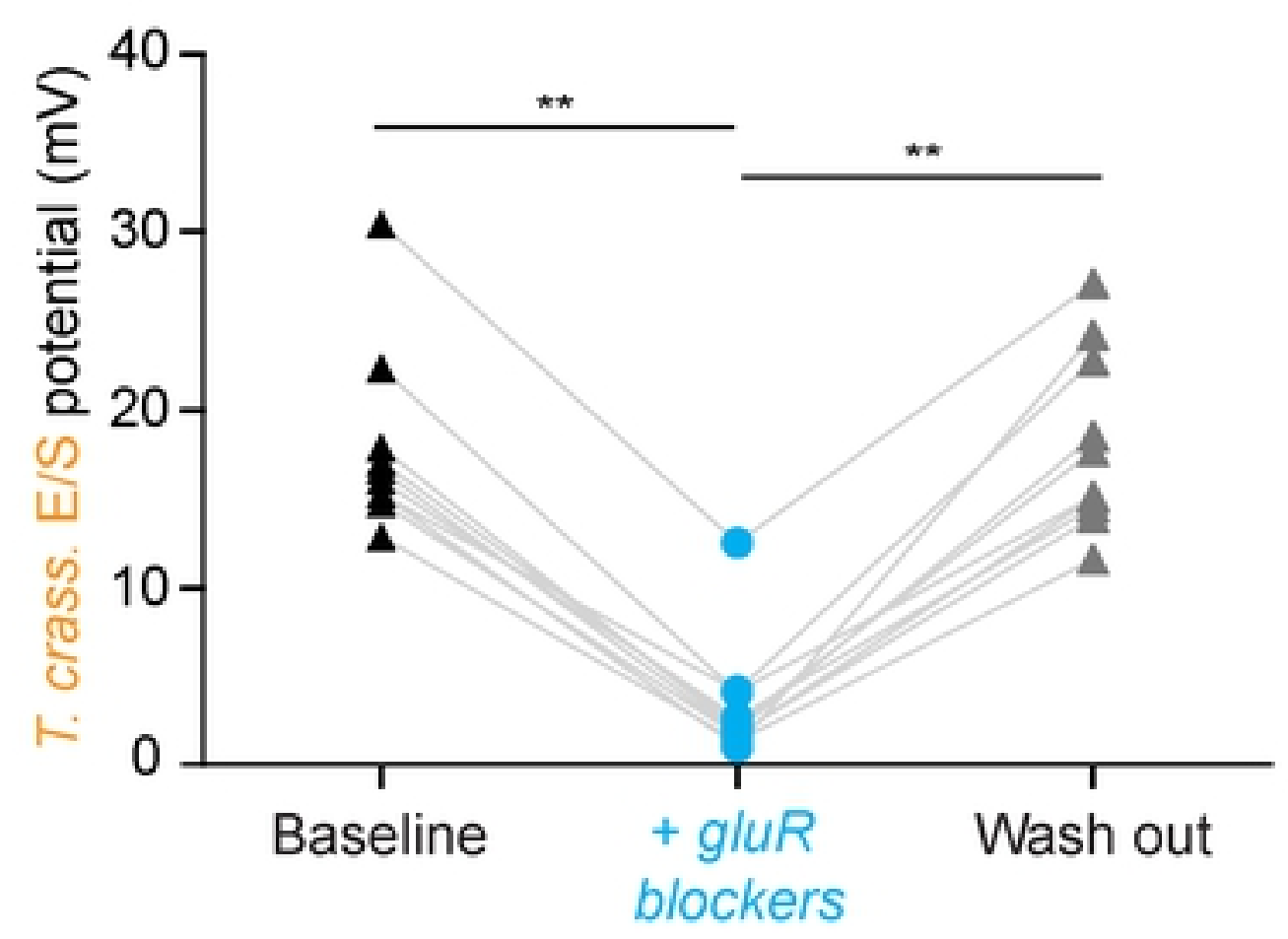

Figure 6: The excitatory effects of Taenia crassiceps are mediated by glutamate receptor activation Figure 6 
A

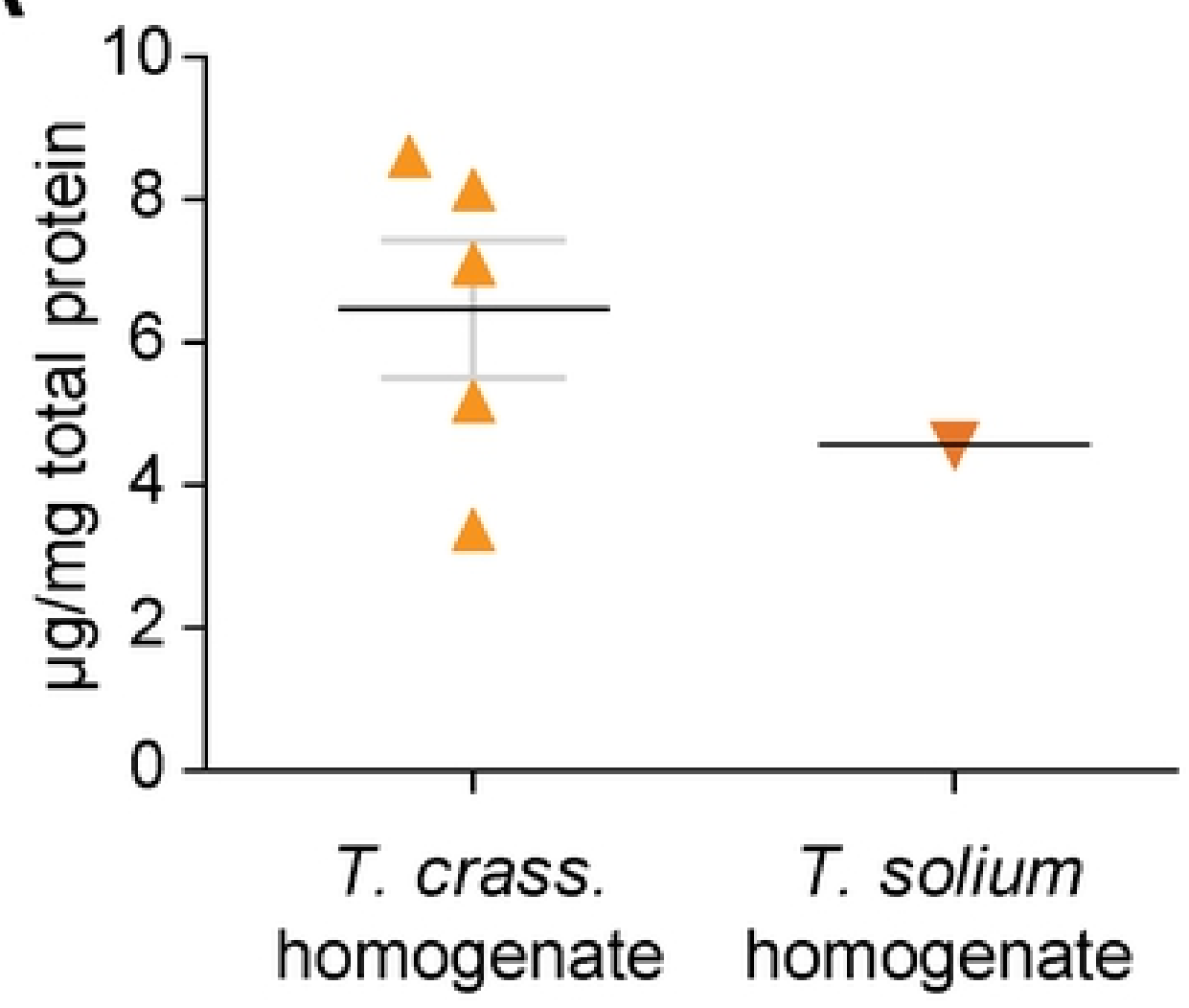

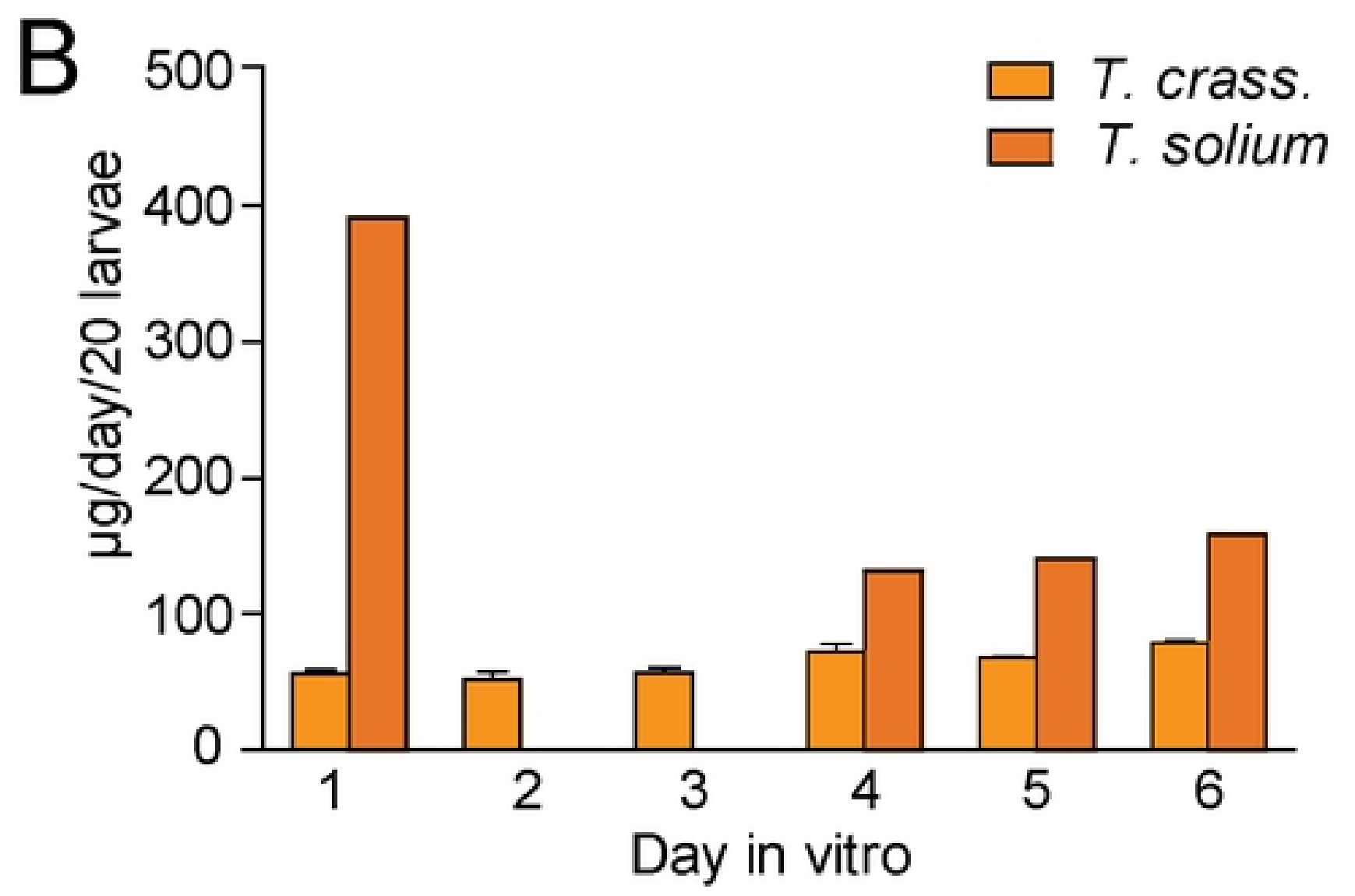

Figure 7: Taenia crassiceps and Taenia solium larvae contain and produce glutamate. 